\title{
Illustrated catalog of Phytoliths from the Galápagos Islands: Economic species of San Cristóbal Island
}

\author{
Fernando J. Astudillo, ${ }^{1,2}$ \\ ${ }^{1}$ Colegio de Ciencias Sociales y Humanidades, Universidad San Francisco de Quito, Quito, Ecuador \\ ${ }^{2}$ Galapagos Science Centre, Galápagos, Ecuador \\ Autor para Correspondencia / Corresponding Author, e-mail: fjastudillo@usfq.edu.ec
}

\section{Catálogo ilustrado de Fitolitos de las Islas Galápagos: Especies económicas de la Isla San Cristóbal}

\begin{abstract}
Native, endemic, and introduced vascular plants from the Galápagos Islands were processed for phytolith extraction. Modern plant specimens of 43 species were collected in the field considering the possible uses of these plant species during the first years of colonization of San Cristóbal Island, Galápagos (1860s). This comparative illustrated catalog is limited to test the production of phytoliths in useful endemic, native, and introduced plant taxa. The results provided the main elements to discriminate morphotypes from native and introduced plants in San Cristóbal. This catalog will guide future paleoethnobotanical research in the Galápagos and other archipelagos of the far eastern Pacific islands.
\end{abstract}

Keywords: Microfossils, Endemic Trees, Comparative Collection, Ecuador.

\section{Resumen}

Especímenes de plantas vasculares nativas, endémicas, e introducidas de las Islas Galápagos fueron procesadas para la extracción de fitolitos. 43 plantas fueron recolectadas considerando los posibles usos de estas especies de plantas durante los primeros años de colonización de la Isla San Cristóbal, Galápagos (1860s). El catálogo ilustrado comparativo que se presenta aquí se limita a explorar la producción de fitolitos en taxones utilizados por los seres humanos. Los resultados proporcionaron los elementos principales para discriminar morfotipos de plantas nativas e introducidas en San Cristóbal. Este catálogo permitirá futuras investigaciones paleoetnobotánicas en las Galápagos y otros archipiélagos de las islas del Pacífico oriental.

Palabras clave: Microfósiles, Arboles Endémicos, Colección Comparativa, Ecuador.

Editado por

Edited by:

Eva O.L. Lantsoght

Recibido /

Received:

26/10/2017

Aceptado /

Accepted:

05/11/2019

Publicado en línea

/ Published online:

20/02/2020

\section{INTRODUCTION}

The Galápagos Islands are considered one of the last pristine natural paradises on Earth. However, during the past four centuries the local plant and animal populations have experienced a constant process of change caused mainly by anthropogenic activity. After accidental discovery by Bishop Tomas de Berlanga in the name of Spain, the 
Galápagos Islands remained seasonally inhabited by pirates and whalers. They were the place later selected by planters to build industrial-size plantations for sugarcane, coffee, and quinine trees (Cinchona pubescens).

The Historical Ecology of the Galápagos Islands project aimed to explore the human history and ecological consequences of human colonization of San Cristóbal Island from an archaeological perspective. The project was divided into four main components for investigating the material and biological remains of El Progreso plantation: zooarchaeology, paleoethnobotany, material culture analysis, and landscape transformation (https://goo.gl/ (pKTpB). As an integral aspect of the paleoethnobotanical component and for comparative purposes, a set of 43 plant samples representing 18 families and 42 species of vascular plants was processed for phytolith extraction during the summers of 2014 and 2015.

The overall goal of this work was to initiate a comparative collection of phytoliths from endemic, native, and introduced plant species existing in the highlands of San Cristóbal Island. The specific objectives were: (1) to identify the production of diagnostic phytoliths; and (2) to catalog the existing diagnostic phytolith morphotypes. Based on published sources, a pre-selection of prominent local taxa to be sampled in the field was used [1-5]. Nine endemic, eleven native, and twenty-two introduced modern plant species were collected considering the possible uses of these plant species during the first years of colonization of San Cristóbal Island. The comparative illustrated catalog presented here is limited to test the production of phytoliths in economic and useful endemic, native, and introduced plant taxa.

\section{STUDY AREA}

The Galápagos are a group of volcanic islands located below the equator in the Pacific Ocean, 1000 km west of the Ecuadorian coast. The Galápagos archipelago comprises approximately 128 named islands and islets formed about three million years ago. The age of the islands increases moving from west to east because of the drift of the Nazca tectonic plate away from the East Pacific Ridge to the southeast over a hotspot [6-8]. This study was located in the southeastern highlands of San Cristóbal, the easternmost and one of the oldest islands in the Galápagos.

The structure of the islands is that of coalescent and/or super-posed lava streams in the lower parts and cones of different pyroclastic material at higher elevations [9]. Soils are formed after decomposition of lava flow surfaces caused by moisture. The modern landscape is covered with poorly developed black soils; older soils are brown Andisoils, and the oldest surfaces show eroded and highly cohesive red soils [10]. Soil pH averages from 6.37 to 6.52 in the humid highlands of San Cristóbal Island (Percy, 2015, personal communication).

Even though the islands are situated on the equator, they do not have a tropical climate due to the influence of two interacting oceanic systems: the Inter Tropical Convergence Zone and El Niño Southern Oscillation [11]. Local climate is influenced by altitude; the average annual temperature oscillates from 20 to $31^{\circ} \mathrm{C}$, and only two seasons are recognized: cool and dry between June and December, and warm and rainy between January and May. The annual precipitation varies from $700-3000 \mathrm{~mm}$ and on the 
windward slopes of the mountains a mist, called garúa, is responsible for continuous humidity throughout the cool season [9].

In Galápagos, approximately 600 plant taxa exist of which about 32\% are endemic. Seven vegetation zones have been defined: Littoral (or Coastal) Zone, Arid Zone, Transition Zone, The Moist Zones: Scalesia Zone, Zanthoxylum (or Brown) Zone, Miconia Zone, Pampa or Fern-Sedge Zone [12]. The environmental setting selected for this project was the Humid Zone (also called the Agricultural Zone or Scalesia Zone), which extends from 200 to 400 $\mathrm{m}$ a.s.I. This zone is home to a variety of endemic taxa such as Scalesia pedunculata, Psidium galapageium, Pisonia floribunda, Adenostemma lavenia, Adiantum henslovianum, Andiatum macrophyllum, Asplenium auritum, Asplenium cristatum, Asplenium formosum, Blechnum occidentale var. puberulum, Blechnum polypodioides, Conyza bonariensis, Desmanthus virgatus, Epidendrum spicatum, Justicia galapagana, Lycopodium dichotomum, Lycopodium passerinoides, Polypodium aureum, Polypodium phyllitidis, Psychotria rufipes, Tournefortia rufo-sericea; and the native trees Cordia lutea and Piscidia carthagenensis [13, 14, 12]. Today, the vegetation is characterized by the presence of invasive trees and shrub species such as guava (Psidium guajava), blackberry (Rubus niveus), plum rose (Syzygium jambos), multicolored lantana (Lantana camara), and several grasses from the genera Brachiaria, Eragrostis, Panicum, and Pennisetum [15].

\section{HUMAN COLONIZATION OF THE GALÁPAGOS ISLANDS}

It is believed that humans never occupied the archipelago before European discovery in 1535. Heyerdahl and Skjølsvold (1974) presented evidence suggesting that preColumbian groups from coastal Peru and Ecuador visited the islands, but this proposition is still in dispute [16]. After independence from Spain in 1822 and separation from Gran Colombia in 1830, the nation of Ecuador claimed the archipelago as national territory. The government then negotiated concessions of some islands for exploiting natural resources and to implement industrial-scale plantations to maintain sovereignty over the islands. In this scheme, Ecuadorian businessmen Manuel J. Cobos, Angel Cobos, and José Monroy obtained a long-term concession to plant and export sugar cane (Saccharum officinarum) and coffee (Coffea arabica L.) from San Cristóbal Island -formerly named Chatham. They created a large plantation called El Progreso in the humid highland interior of the island, $1000 \mathrm{~km}$ west of the South American Pacific coast (Fig. 1).

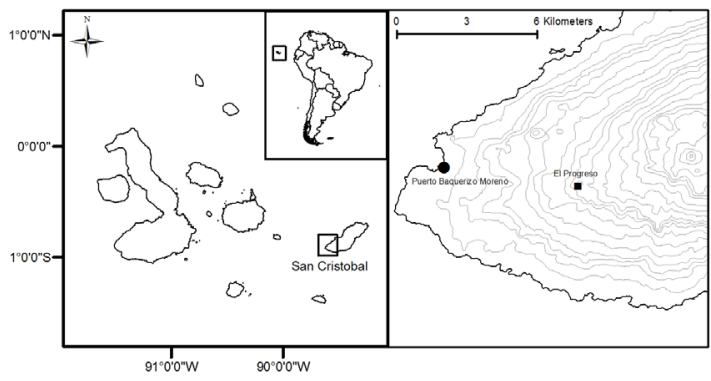

FIGURE 1. El Progreso Plantation operated in the humid highlands of San Cristóbal Island, $7 \mathrm{~km}$ east of the modern port city of Puerto Baquerizo Moreno. Modern plants for phytolith extraction were collected in the proximities of the modern village, also named El Progreso. 
This industrial-scale plantation occupied most of the southwestern portion of the island. By 1904 El Progreso plantation was producing approximately 500 tons/yr. of sugar and great quantities of alcohol. Water was extracted from one of the few sources of fresh water in the entire archipelago, El Junco Lake, located $7 \mathrm{~km}$ away in the interior of the island. Over $100 \mathrm{~km}$ of roads were constructed and a 10-km railroad transported sugar products, coffee, tortoise oil, lime, salted and dried fish, meat, and leather to a deep-water port. Almost 400 laborers lived and worked on the plantation [17, 18]. The hacienda ceased operations in 1917. Since then, smallholder farmers have occupied some of the original El Progreso lands. Weeds invaded the abandoned fields and the useable machinery was returned to the mainland or removed by the remaining workers and visitors [18]. Today, the original hacienda land is a modern parish of the Province of Galápagos and is divided into small parcels used for farming.

\section{METHODS AND LABORATORY PROTOCOLS}

The plant specimens for this collection were collected during the summers of 2014 and 2015 in the proximity of El Progreso village $(-0.90734,-89.55833 ; 334 \mathrm{~m}$ a.s.l.). Sections of leaves, stem, and wood were used to explore the presence and production of diagnostic phytoliths (Table 1).

Phytolith extraction from modern samples followed "dry ashing" protocols outlined by Albert and Weiner (2001) [19], with minor modifications from Mercader et al. (2011, 2010) $[20,21]$ and Astudillo (2018) [22]. The samples were processed in the laboratories of the Galápagos Science Centre (UNC-Chapel Hill) in Ecuador and Simon Fraser University in Canada. The protocol is ordered in four steps.

TABLE 1. Plants collected in San Cristóbal for phytoliths extraction Key: $\mathrm{L}=$ leaves; $\mathrm{S}=$ stem; $\mathrm{W}=$ wood $/ \mathrm{bark} ; \mathrm{F}=$ flowers

\begin{tabular}{|c|c|c|c|c|}
\hline Family & Species & Parts & Category & TAL No. \\
\hline Asteraceae & Scalesia pedunculata Hook. f. & $L, S$ & Endemic & GLP-PRG-PLB-REF 4 \\
\hline Bombaceae & Ceiba pentandra (L.) Gaertn. & $L, S, W$ & Introduced & GLP-PRG-PLB-REF 21 \\
\hline Boraginaceae & Tournefortia pubescens Hook.f. & $L, S$ & Endemic & GLP-PRG-PLB-REF 25 \\
\hline Boraginaceae & Cordia lutea Lam. & L, S & Native & GLP-PRG-PLB-REF 32 \\
\hline Boraginaceae & Tournefortia rufo-sericea Hook. f. & $\mathrm{L}, \mathrm{S}, \mathrm{W}$ & Endemic & GLP-PRG-PLB-REF 39 \\
\hline Burseraceae & Bursera graveolens (Kunth) Triana \& Planch. & $\mathrm{L}, \mathrm{S}, \mathrm{W}$ & Native & GLP-PRG-PLB-REF 41 \\
\hline Cupressaceae & Cupressus macrocarpa Hartw. & $\mathrm{L}, \mathrm{S}, \mathrm{W}$ & Introduced & GLP-PRG-PLB-REF 36 \\
\hline Cyperaceae & Rhynchospora nervosa ssp. Ciliate (G. Mey.) T. Koyama & $\mathrm{L}, \mathrm{F}$ & Native & GLP-PRG-PLB-REF 15 \\
\hline Cyperaceae & Scleria melaleuca Rchb. Ex Schltdl. \& Cham. & $L, F$ & Native & GLP-PRG-PLB-REF 16 \\
\hline Euphorbiaceae & Aleurites moluccana (L.) Willd. & $L, S, W$ & Introduced & GLP-PRG-PLB-REF 28 \\
\hline Euphorbiaceae & Croton scouleri var. scouleri Hook. f. & $L, S$ & Endemic & GLP-PRG-PLB-REF 29 \\
\hline Euphorbiaceae & Hippomane mancinella $\mathrm{L}$. & $L, S, W$ & Native & GLP-PRG-PLB-REF 40 \\
\hline Fabaceae & Piscidia carthagenensis Jacq. & L, S & Native & GLP-PRG-PLB-REF1 \\
\hline Lauraceae & Persea americana Mill. & $L, S, W$ & Introduced & GLP-PRG-PLB-REF 35 \\
\hline Malvaceae & Gossypium darwinii G. Watt. & $\mathrm{L}, \mathrm{S}, \mathrm{W}$ & Endemic & GLP-PRG-PLB-REF 42 \\
\hline
\end{tabular}




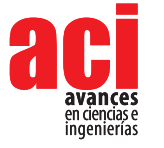

\begin{tabular}{|c|c|c|c|c|}
\hline Family & Species & Parts & Category & TAL No. \\
\hline Malvaceae & Miconia robinsoniana Cong. & $\mathrm{L}, \mathrm{S}, \mathrm{W}$ & Endemic & GLP-PRG-PLB-REF $43(\mathrm{a} / \mathrm{b})$ \\
\hline Mimosaceae & Inga insignis Knuth. & W & Introduced & GLP-PRG-PLB-REF 33 \\
\hline Mimosaceae & Prosopisjuliflora (Sw.) & $\mathrm{L}, \mathrm{S}, \mathrm{W}$ & Native & GLP-PRG-PLB-REF 34 \\
\hline Moraceae & Artocarpus altilis (Parkinson) Fosberg & $L, S$ & Introduced & GLP-PRG-PLB-REF 44 \\
\hline Myrtaceae & Psidium galapageium var. howellii Porter & $L, S$ & Endemic & GLP-PRG-PLB-REF 2 \\
\hline Myrtaceae & Syzygium jambos (L.) Alston & $L, S$ & Introduced & GLP-PRG-PLB-REF 3 \\
\hline Myrtaceae & Psidium guajava $\mathrm{L}$. & L, S & Introduced & GLP-PRG-PLB-REF 8 \\
\hline Poaceae & Bambusa vulgaris var. vittata Rivière \& C. Rivière & $\mathrm{L}, \mathrm{S}, \mathrm{W}$ & Introduced & GLP-PRG-PLB-REF 22 \\
\hline Poaceae & Bambusa vulgaris var. vulgaris Schrad ex Wendle & $\mathrm{L}, \mathrm{S}, \mathrm{W}$ & Introduced & GLP-PRG-PLB-REF 23 \\
\hline Poaceae & Brachiaria decumbens Stapf. & $L, F$ & Introduced & GLP-PRG-PLB-REF 14 \\
\hline Poaceae & Cynodon nlemfuensis Vanderyst & L & Introduced & GLP-PRG-PLB-REF 11 \\
\hline Poaceae & Digitaria sp. & $L, F$ & Introduced & GLP-PRG-PLB-REF 19 \\
\hline Poaceae & Eleusine indica (L.) Gaertn. & $L, F$ & Introduced & GLP-PRG-PLB-REF 17 \\
\hline Poaceae & Eragrostis amabilis (L.) Wight \& Arn. ex Nees & $L, F$ & Introduced & GLP-PRG-PLB--REF 18 \\
\hline Poaceae & Panicum maximum Jacq. & $L, F$ & Introduced & GLP-PRG-PLB-REF $10 \& 12$ \\
\hline Poaceae & Pennisetum purpureum Schum. & $L, F$ & Introduced & GLP-PRG-PLB-REF 13 \\
\hline Poaceae & Saccharum officinarum $\mathrm{L}$. & L & Introduced & GLP-PRG-PLB-REF 5, 6, \& 9 \\
\hline Poaceae & Stenotaphrum secundatum (Walter) Kuntze & $\mathrm{L}$ & Native & GLP-PRG-PLB-REF 20 \\
\hline Rubiaceae & Coffea arabica L. & $L, S$ & Introduced & GLP-PRG-PLB-REF 7 \\
\hline Rubiaceae & Psychotria rufipes Hook. f. & $\mathrm{L}, \mathrm{S}$ & Endemic & GLP-PRG-PLB-REF 30 \\
\hline Rutaceae & Citrus paradisi Macfad. & $\mathrm{L}, \mathrm{S}, \mathrm{W}$ & Introduced & GLP-PRG-PLB-REF 31 \\
\hline Rutaceae & Zanthoxylum fagara (L.) Sarg. & $\mathrm{L}, \mathrm{S}, \mathrm{W}$ & Native & GLP-PRG-PLB-REF 37 \\
\hline Rutaceae & Citrus sinensis (L.) Osbeck & W & Introduced & GLP-PRG-PLB-REF 38 \\
\hline Solanaceae & Solanum cheesmaniaef. cheesmaniae (Riley) Fosberg & $L, S$ & Endemic & GLP-PRG-PLB-REF 24 \\
\hline Urticaceae & Laportea aestuans (L.) Chew & $L, S$ & Native & GLP-PRG-PLB-REF $26 \& 27$ \\
\hline
\end{tabular}

(1) The plant tissue was cleaned by immersion in a soap solution to eliminate residues of soil or other kinds of impurities. Specimens were then dried overnight at $\sim 100^{\circ} \mathrm{C}$ in an incubator oven. After cooling, plant mass was weighed on a precision balance.

(2) The dry samples then went into a muffle furnace for combustion over the course of 36 hours at $500^{\circ} \mathrm{C}$. Ceramic crucibles of 30 and $50 \mathrm{ml}$ with lids were used. (3) The mass of the resulting ash was weighed in a precision balance and received a $10 \mathrm{ml}$ 50:50 solution made of hydrochloric $(\mathrm{HCl})$ and nitric $\left(\mathrm{HNO}_{3}\right)$ acids at $3 \mathrm{~N}$. After acid reactions, the samples were placed to boil at $\sim 70^{\circ} \mathrm{C}$ until a gelatin matrix was formed. After cooling, successive washing cycles removed acids from the sample by 5 -minute centrifugation cycles at 3,000 r.p.m. When acid elimination was complete the remainder of a sample was dried overnight at $\sim 100^{\circ} \mathrm{C}$ and weighed. Phosphate and carbonate loss was estimated by calculating mass differential. After this, approximately $10 \mathrm{ml}$ of hydrogen peroxide $\left(\mathrm{H}_{2} \mathrm{O}_{2}\right)$ at 30\% was added to the sample to tear down organic matter. The sample was dried at $\sim 100^{\circ} \mathrm{C}$ overnight.

(4) The resulting biominerals form the acid-insoluble fraction (A.I.F.) where phytoliths, among other biogenic precipitates, are present. An aliquot of $\sim 0.001 \mathrm{~g}$ was taken for 
mounting, after proper mixing. The mounting medium was made up of two droplets of resin solution 'Entellan new'. The aliquot was well mixed, and the microscopic inspection and counting took place within 48 hours of mounting before media were able to dry (3-D shifting of phytoliths was necessary to carry out identification).

Classifying criteria followed those presented by the International Code for Phytolith Nomenclature 1.0 [23] and the published literature for studies of phytoliths in archaeological sites in the Neo-tropics [24-35]; for grass phytoliths identification [36-49]; and for sugarcane and bamboo phytoliths identification [50,51] (Table 2). Morphological features scrutinized were size, bi-dimensional outline, three-dimensional classification, and surface texture. All samples were analyzed under differential interference contrast (D.I.C.) microscopy at 40X magnification in 10 adjacent but not overlapping lines across the cover slip. Close examination of phytolith morphology was conducted on photographic frames using the image analysis software OLYMPUS Stream Basic 1.8 in a research microscope Olympus BX53 D.I.C.

TABLE 2. Classifying criteria

\begin{tabular}{|c|c|c|}
\hline \multicolumn{2}{|r|}{ Morphotype } & Sources \\
\hline 1 & Acicular columellate hair cell & This study \\
\hline 2 & Acicular equal prickle & This study \\
\hline 3 & Acicular hair cell & Piperno 2006 \\
\hline 4 & Bilobate concave outer margin short shaft & Fahmy (2008:15) \\
\hline 5 & Carinate facetate bulliform & This study \\
\hline 6 & Clavate facetate & This study \\
\hline 7 & Clavate columellate hair cell & This study \\
\hline 8 & Collapsed saddle & Piperno 2006 \\
\hline 9 & Cuneiform bulliform & Madella et al. 2005; Gu et al., 2016 \\
\hline 10 & Cylindrical striate & This study \\
\hline 11 & Cylindrical sulcate tracheid & Madella et al. 2005 \\
\hline 12 & Elliptical rugulate & This study \\
\hline 13 & Elongate cylindrical psilate & This study \\
\hline 14 & Elongate echinate & Dickau et al. 2013 \\
\hline 15 & Elongate echinate long cell & Madella et al. 2005 \\
\hline 16 & Fusiform equal & This study \\
\hline 17 & Globular sinuate & This study \\
\hline 18 & Glume & Piperno 2006 \\
\hline 19 & Hair base & Piperno 2006 \\
\hline 20 & Irregular equal & This study \\
\hline 21 & Mesophyll epidermal & Piperno 2006 \\
\hline 22 & Oblong columellate epidermal & This study \\
\hline
\end{tabular}




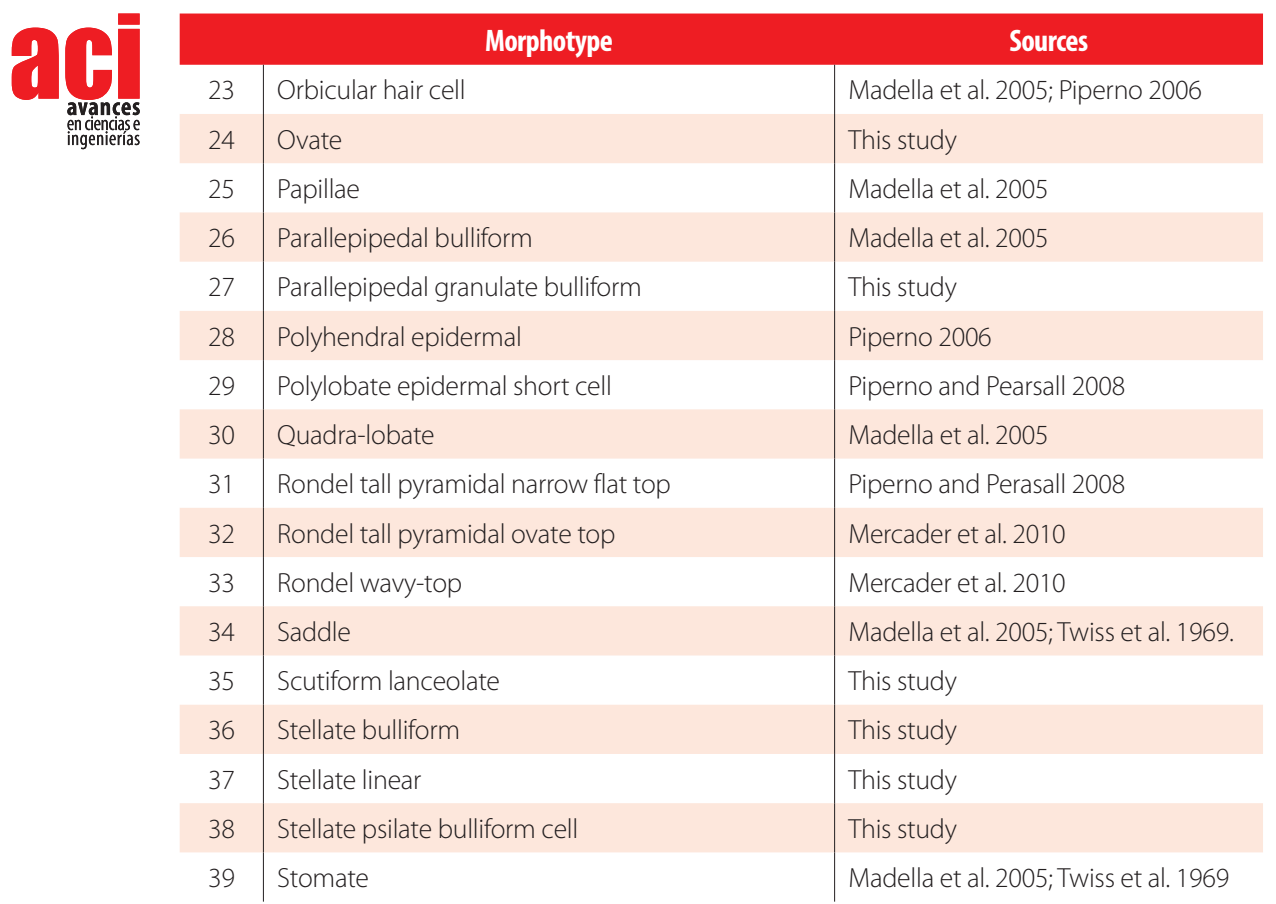

\section{RESULTS}

\section{Biogenic Production}

Biogenic content is the total percentage of phytoliths, silica, and diatoms produced by plants. The biogenic content of the comparative material from San Cristóbal Island are expressed in Table 3, where higher values in the Acid Insoluble Fraction (A.I.F.) indicate greater silica production. In native and endemic woody plants in San Cristóbal Island, biogenic silica production averages from $0.13 \%$ to $2.93 \%$ of the plant's dry mass; the highest amount of silica was produced by Tournefortia pubescens (Boraginaceae). In native/endemic grasses and members of the Cyperaceae family, the silica presence variates from $0.79 \%$ to $2.97 \%$.

Typical ash production is between $0.95 \%$ and $6.78 \%$ of the original mass on introduced grass species, and between $0.10 \%$ and $1.23 \%$ on introduced woody plants. The absolute highest biogenic content ( $>6 \%$ ) has been recorded among introduced members of C3 grasses from the Poaceae family: Bambusa vulgaris and Panicum maximum; while the lowest silica production $(<0.09 \%)$ is noticed in members of the Asrestaceae (Scalesia pedunculata), Bombaceae (Ceiba petandra), Cupressaceae (Cupressus macrocarpa), Euphorbiaceae (Croton scouleri and Hippomane mancinella), Malvaceae (Gossypium darwinii and Miconia robinsoniana), Mimoseae (Prosopis juliflora), Myrtaceae (Psidium guajava), and Rubiaceae (Coffea arabica). 
TABLE 3. Biogenic production of phytoliths from modern plants of San Cristóbal Island. Key: $\mathrm{L}=$ leaves; $\mathrm{S}=$ stem; $\mathrm{W}=$ wood $/$ bark; $\mathrm{F}=$ flowers

\begin{tabular}{|c|c|c|c|c|c|c|}
\hline Family & Species & Part & $\begin{array}{l}\text { Dry mass } \\
\text { (g) }\end{array}$ & $\begin{array}{l}\text { Ash } \\
(g)\end{array}$ & $\begin{array}{l}\text { A.I.F. } \\
(g)\end{array}$ & $\begin{array}{l}\text { A.I.F } \\
(\%)\end{array}$ \\
\hline Asteraceae & Scalesia pedunculata Hook. f. & L, S & 1.976 & 0.192 & 0.001 & 0.051 \\
\hline Bombaceae & Ceiba pentandra (L.) Gaertn. & $L, S, W$ & 3.644 & 0.598 & 0.001 & 0.027 \\
\hline \multirow[t]{3}{*}{ Boraginaceae } & Tournefortia pubescens Hook. f. & $L, S$ & 1.360 & 0.159 & 0.041 & 3.015 \\
\hline & Cordia lutea Lam. & $L, S$ & 2.885 & 0.351 & 0.007 & 0.243 \\
\hline & Tournefortia rufo-sericea Hook. f. & $\mathrm{L}, \mathrm{S}, \mathrm{W}$ & 3.180 & 0.309 & 0.004 & 0.126 \\
\hline Burseraceae & Bursera graveolens (Kunth) Triana \& Planch. & $\mathrm{L}, \mathrm{S}, \mathrm{W}$ & 3.189 & 0.170 & 0.011 & 0.345 \\
\hline Cupressaceae & Cupressus macrocarpa Hartw. & $L, S, W$ & 7.878 & 0.424 & 0.001 & 0.013 \\
\hline \multirow[t]{2}{*}{ Cyperaceae } & $\begin{array}{c}\text { Rhynchospora nervosa ssp. Ciliate (G. Mey.) T. } \\
\text { Koyama }\end{array}$ & $L, F$ & 0.538 & 0.061 & 0.002 & 0.372 \\
\hline & Scleria melaleuca Rchb. Ex Schltdl. \& Cham. & $L, F$ & 2.084 & 0.393 & 0.061 & 2.927 \\
\hline \multirow[t]{3}{*}{ Euphorbiaceae } & Aleurites moluccana (L.) Willd. & $L, S, W$ & 1.902 & 0.198 & 0.002 & 0.105 \\
\hline & Croton scouleri var. scouleri Hook. f. & $L, S$ & 1.753 & 0.250 & 0.001 & 0.057 \\
\hline & Hippomane mancinella $\mathrm{L}$. & $L, S, W$ & 4.205 & 0.410 & 0.003 & 0.071 \\
\hline Fabaceae & Piscidia carthagenensis Jacq. & $L, S$ & 2.005 & 0.133 & 0.003 & 0.150 \\
\hline Lauraceae & Persea americana Mill. & $L, S$ & 2.474 & 0.099 & 0.004 & 0.162 \\
\hline \multirow[t]{3}{*}{ Malvaceae } & Gossypium darwinii G. Watt. & $\mathrm{L}, \mathrm{S}, \mathrm{W}$ & 3.761 & 0.351 & 0.001 & 0.027 \\
\hline & Miconia robinsoniana Cogn. & $L, S, F$ & 4.429 & 0.198 & 0.002 & 0.045 \\
\hline & Miconia robinsoniana Cogn. & $\mathrm{L}, \mathrm{S}, \mathrm{F}$ & 2.993 & 0.246 & 0.001 & 0.033 \\
\hline \multirow{2}{*}{ Mimosaseae } & Inga insignis Knuth. & W & $\mathrm{n} / \mathrm{a}$ & n/a & $\mathrm{n} / \mathrm{a}$ & n/a \\
\hline & Prosopis juliflora (Sw.) & $L, S, W$ & 5.344 & 0.293 & 0.026 & 0.487 \\
\hline Moraceae & Artocarpus altilis (Parkinson) Fosberg. & $L, S$ & 3.919 & 0.856 & 0.048 & 1.225 \\
\hline \multirow[t]{3}{*}{ Myrtaceae } & Psidium galapageium var. howellii Porter. & $L, S$ & 2.710 & 0.180 & 0.007 & 0.258 \\
\hline & Psidium guajava $\mathrm{L}$. & $\mathrm{L}, \mathrm{S}$ & 3.442 & 0.167 & 0.001 & 0.029 \\
\hline & Syzygium jambos (L.) Alston. & $\mathrm{L}, \mathrm{S}$ & 2.842 & 0.147 & 0.023 & 0.809 \\
\hline Poaceae & Bambusa vulgaris var. vittata Rivière \& C. Rivière. & $L, S$ & 2.630 & 0.232 & 0.175 & 6.654 \\
\hline \multirow[t]{8}{*}{ Poaceae } & Bambusa vulgaris var. vulgaris Schrad ex Wendle. & $L, S$ & 1.194 & 0.146 & 0.081 & 6.784 \\
\hline & Brachiaria decumbens Stapf. & $L, F$ & 1.404 & 0.165 & 0.039 & 2.778 \\
\hline & Cynodon nlemfuensis Vanderyst. & $L$ & 1.744 & 0.192 & 0.030 & 1.720 \\
\hline & Digitaria sp. & $L, F$ & 3.521 & 0.193 & 0.020 & 0.568 \\
\hline & Eleusine indica (L.) Gaertn. & $L, F$ & 2.206 & 0.092 & 0.021 & 0.952 \\
\hline & Eragrostis amabilis (L.) Wight \& Arn. Ex Nees. & $L, F$ & 1.062 & 0.094 & 0.041 & 3.861 \\
\hline & Panicum sp. & $L, F$ & 0.985 & 0.140 & 0.064 & 6.497 \\
\hline & Panicum maximum Jacq & $L, F$ & 1.371 & 0.205 & 0.045 & 3.282 \\
\hline
\end{tabular}




\begin{tabular}{|c|c|c|c|c|c|c|c|}
\hline 1 & Family & Species & Part & $\begin{array}{l}\text { Dry mass } \\
\text { (g) }\end{array}$ & $\begin{array}{l}\text { Ash } \\
\text { (g) }\end{array}$ & $\begin{array}{l}\text { A.I.F. } \\
\text { (g) }\end{array}$ & $\begin{array}{r}\text { A.I.F } \\
(\%)\end{array}$ \\
\hline \multirow{13}{*}{$\begin{array}{l}\text { avances } \\
\text { enciencicese } \\
\text { ingenierias }\end{array}$} & & Pennisetum purpureum Schum. & $L, F$ & 1.640 & 0.243 & 0.069 & 4.207 \\
\hline & & Saccharum officinarum $\mathrm{L}$. & L & 2.977 & 0.326 & 0.095 & 3.191 \\
\hline & & Saccharum officinarum $\mathrm{L}$. & $\mathrm{L}$ & 3.170 & 0.437 & 0.060 & 1.893 \\
\hline & & Saccharum officinarum $\mathrm{L}$. & $\mathrm{L}$ & 1.861 & 0.289 & 0.000 & 0.000 \\
\hline & & Stenotaphrum secundatum (Walter) Kuntze. & $\mathrm{L}$ & 3.644 & 0.141 & 0.029 & 0.796 \\
\hline & Rubiaceae & Coffea arabica $\mathrm{L}$. & $L, S$ & 2.498 & 0.167 & 0.001 & 0.040 \\
\hline & & Psychotria rufipes Hook. f. & $\mathrm{L}, \mathrm{S}$ & 2.007 & 0.162 & 0.002 & 0.100 \\
\hline & Rutaceae & Citrus paradisi Macfad. & $\mathrm{L}, \mathrm{S}, \mathrm{W}$ & 4.110 & 0.444 & 0.005 & 0.122 \\
\hline & & Zanthoxylum fagara (L.) Sarg. & $\mathrm{L}, \mathrm{S}, \mathrm{W}$ & 1.878 & 0.164 & 0.005 & 0.266 \\
\hline & & Citrus sinensis (L.) Osbeck & W & $\mathrm{n} / \mathrm{a}$ & $n / a$ & $\mathrm{n} / \mathrm{a}$ & $n / a$ \\
\hline & Solanaceae & $\begin{array}{c}\text { Solanum cheesmaniaef. cheesmaniae (Riley) } \\
\text { Fosberg }\end{array}$ & $L, S$ & 0.961 & 0.172 & 0.001 & 0.104 \\
\hline & Urticaceae & Laportea aestuans (L.) Chew & $L, S$ & 0.496 & 0.118 & 0.007 & 1.411 \\
\hline & & Laportea aestuans (L.) Chew. & $L, S$ & 0.742 & 0.204 & 0.012 & 1.617 \\
\hline
\end{tabular}


Phytoliths in Modern Plant Taxa.

San Cristóbal Island, Galápagos

\subsection{Asteraceae. Scalesia pedunculata Hook. f.}

Common name: Scalesia / Lechoso

Origin: Endemic

Part Processed: Leaf, stem

Density: LoW

Morphotypes: (A) Globular sinuate; (B) hair base; (C) mesophyll epidermal phytoliths; (D) orbicular hair cell
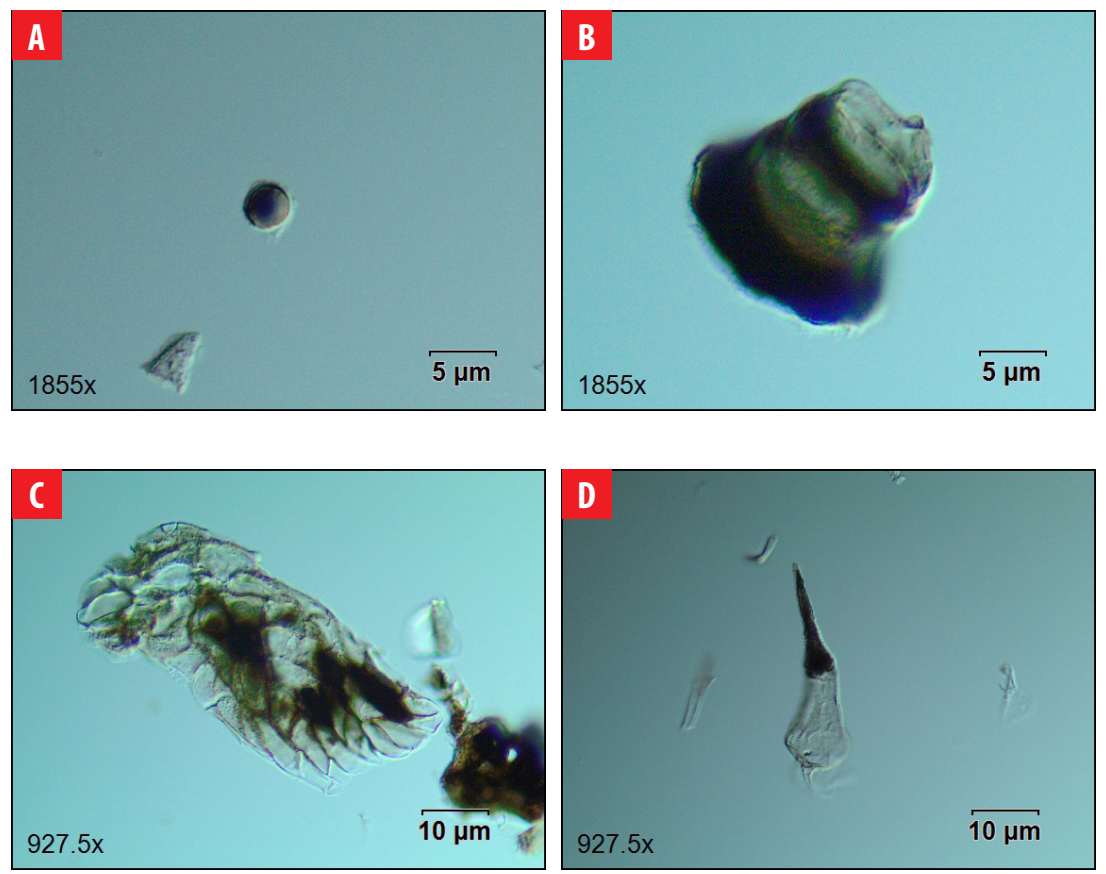
4.2 Bombaceae. Ceiba pentandra (L.) Gaertn.

Common name: Silk cotton tree / Ceibo

Origin: Introduced (Cultivated)

Part Processed: Leaf, stem, wood

Density: LoW

Morphotypes: (A) Clavate columellate hair cell; (B) acicular hair cell; (C) globular phytolith
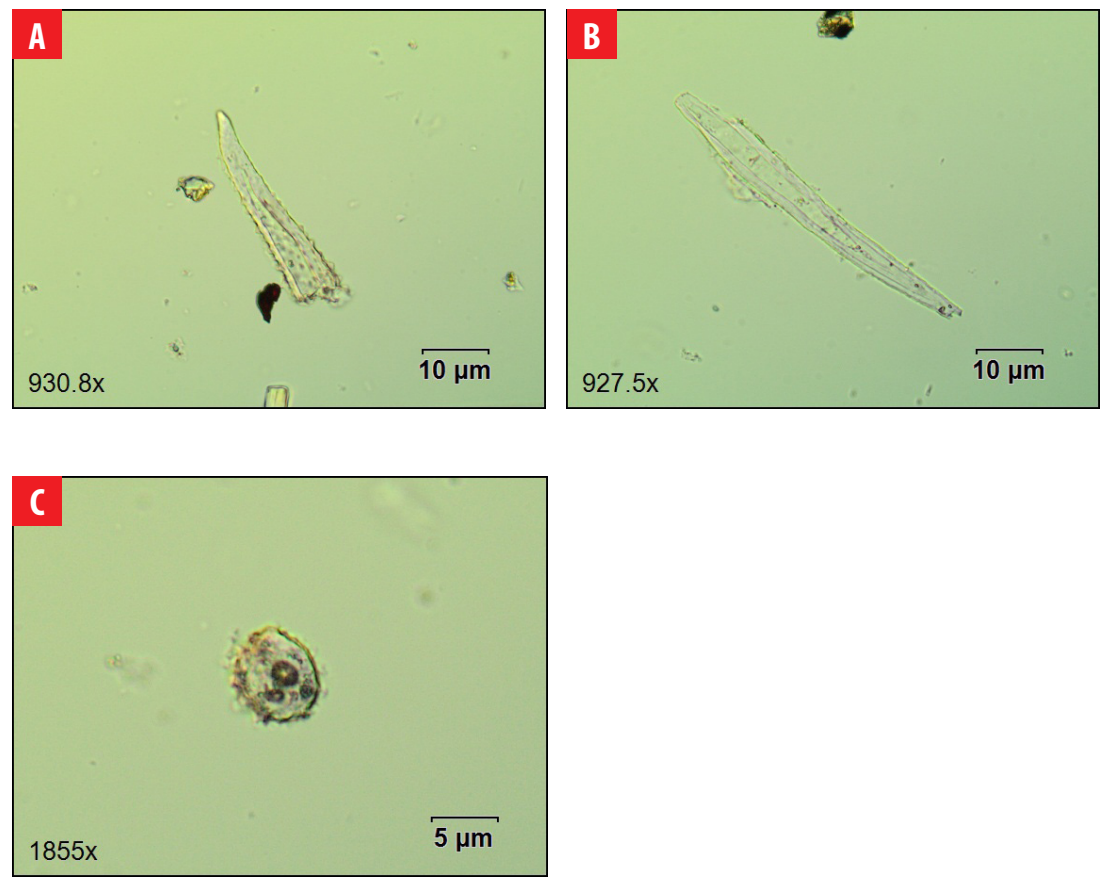
4.3 Boraginaceae. Tournefortia pubescens Hook. f.

Common name: White haired tournefortia / Lengua de Vaca

Origin: Endemic

Part Processed: Leaf, stem

Density: High

Morphotypes: (A) Cylindrical striate long cell; (B) hair base; (C \& D) polyhedral epidermal phytoliths
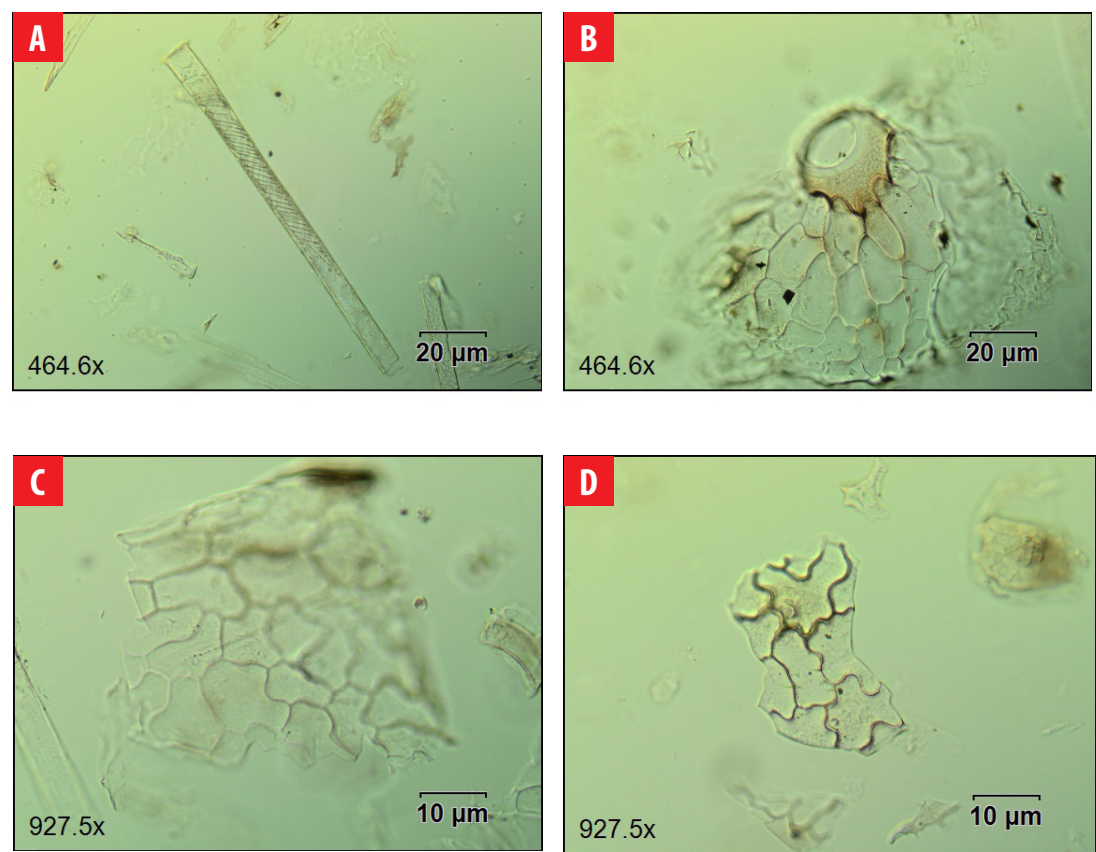


\subsection{Boraginaceae. Cordia lutea Lam.}

Common name: Yellow cordia / Muyuyo

Origin: Native (Indigenous taxon)

Part Processed: Leaf, stem

Density: Low

Morphotypes: (A-E) Clavate columellate hair cell; (F) stellate bulliform cell
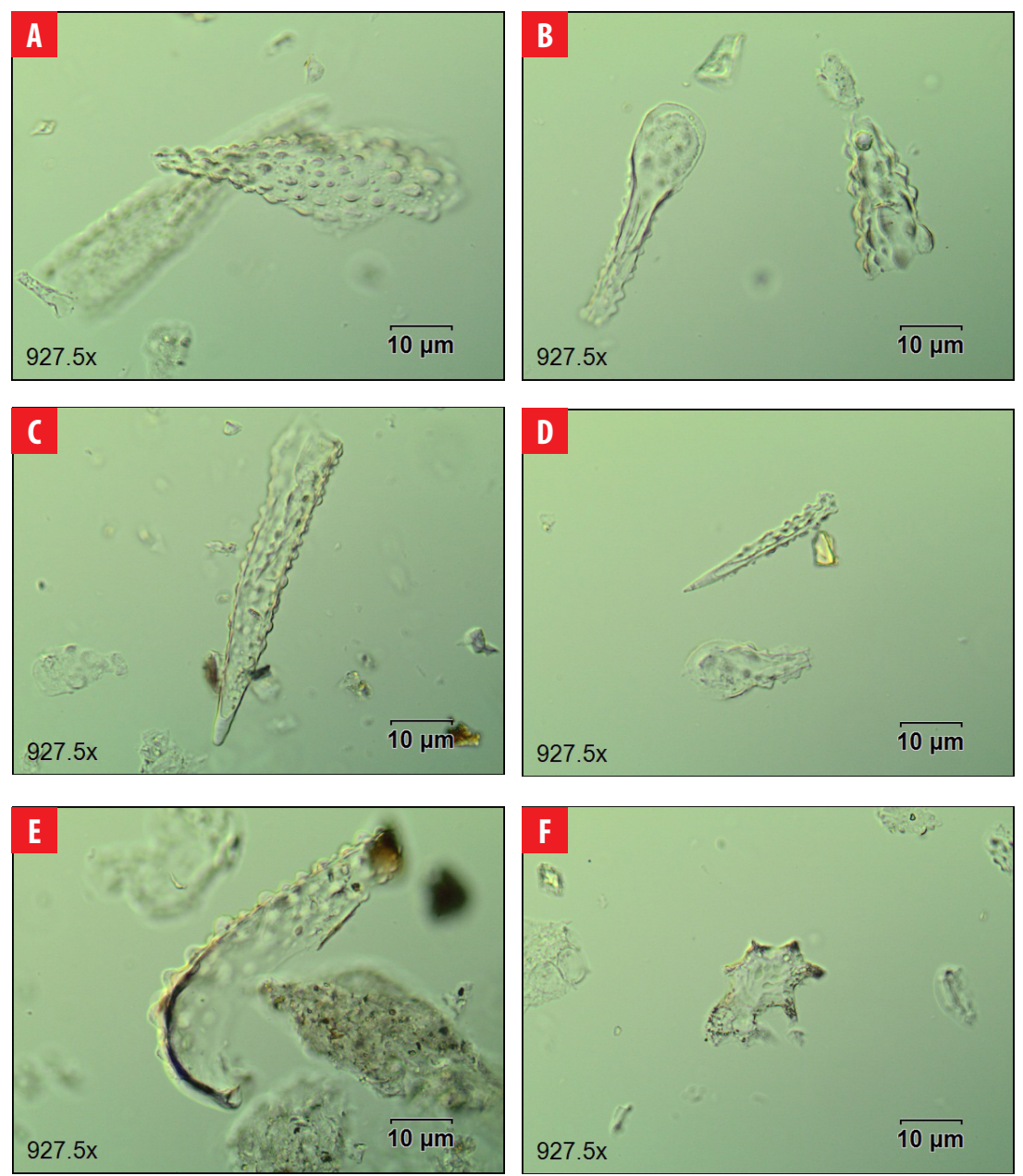
4.5 Boraginaceae. Tournefortia rufo-sericea Hook. f.

Common name: Red haired tournefortia / Palito Negro

Origin: Endemic

Part Processed: Leaf, stem, wood

Density: Low

Morphotypes: Hair base
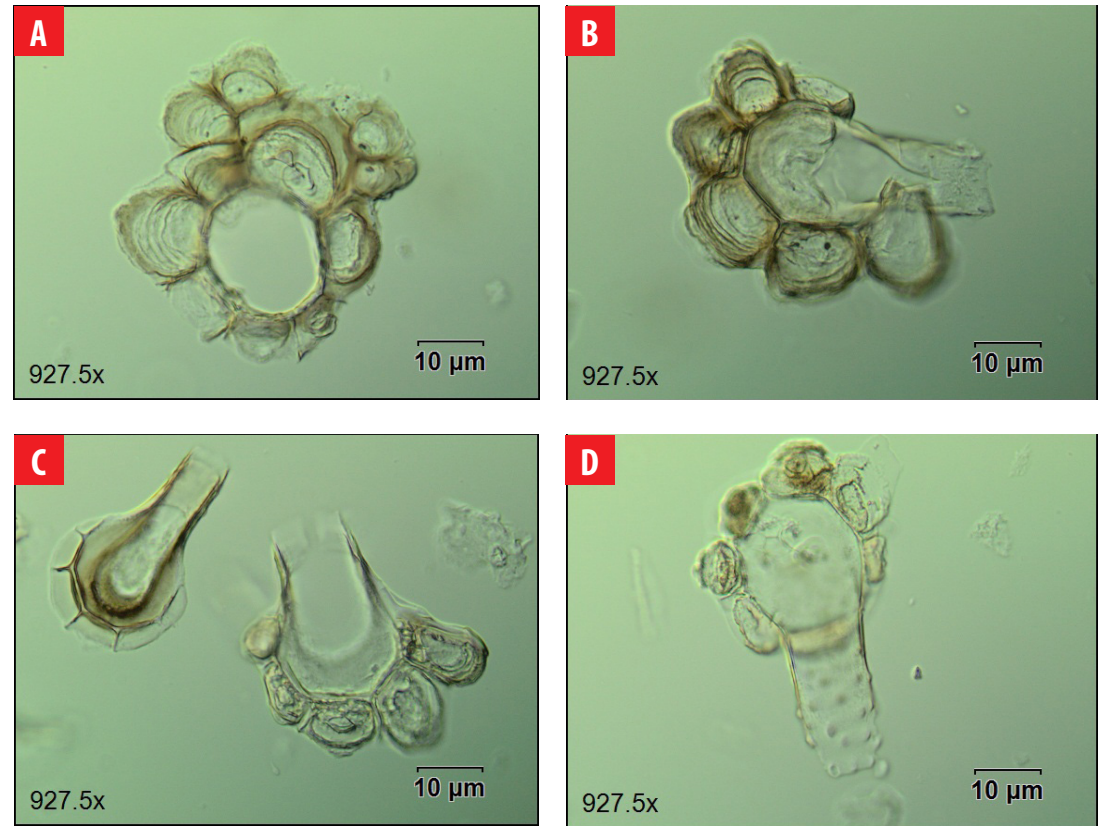

4.6 Burseraceae. Bursera graveolens (Kunth) Triana \& Planch.

Common name: Incense tree / Palo Santo

Origin: Native (Indigenous taxon)

Part Processed: Leaf, stem, wood

Density: LoW

Morphotypes: Mesophyll epidermal phytoliths
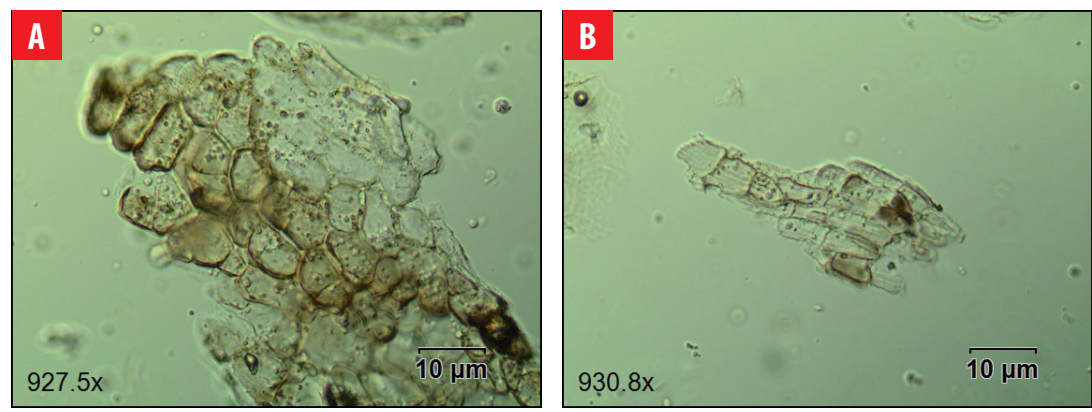
4.7 Cyperaceae. Rhynchospora nervosa ssp. Ciliate (G. Mey.) T. Koyama

Origin: Native (Indigenous taxon)

Part Processed: Leaf, stem

Density: Low

Morphotypes: (A) Glume phytoliths; (B) globular phytoliths; (C) papillae cell; (D) parallepipedal bulliform cell; (E) parallepipedal granulate bulliform cell; (F) polyhedral epidermal phytoliths
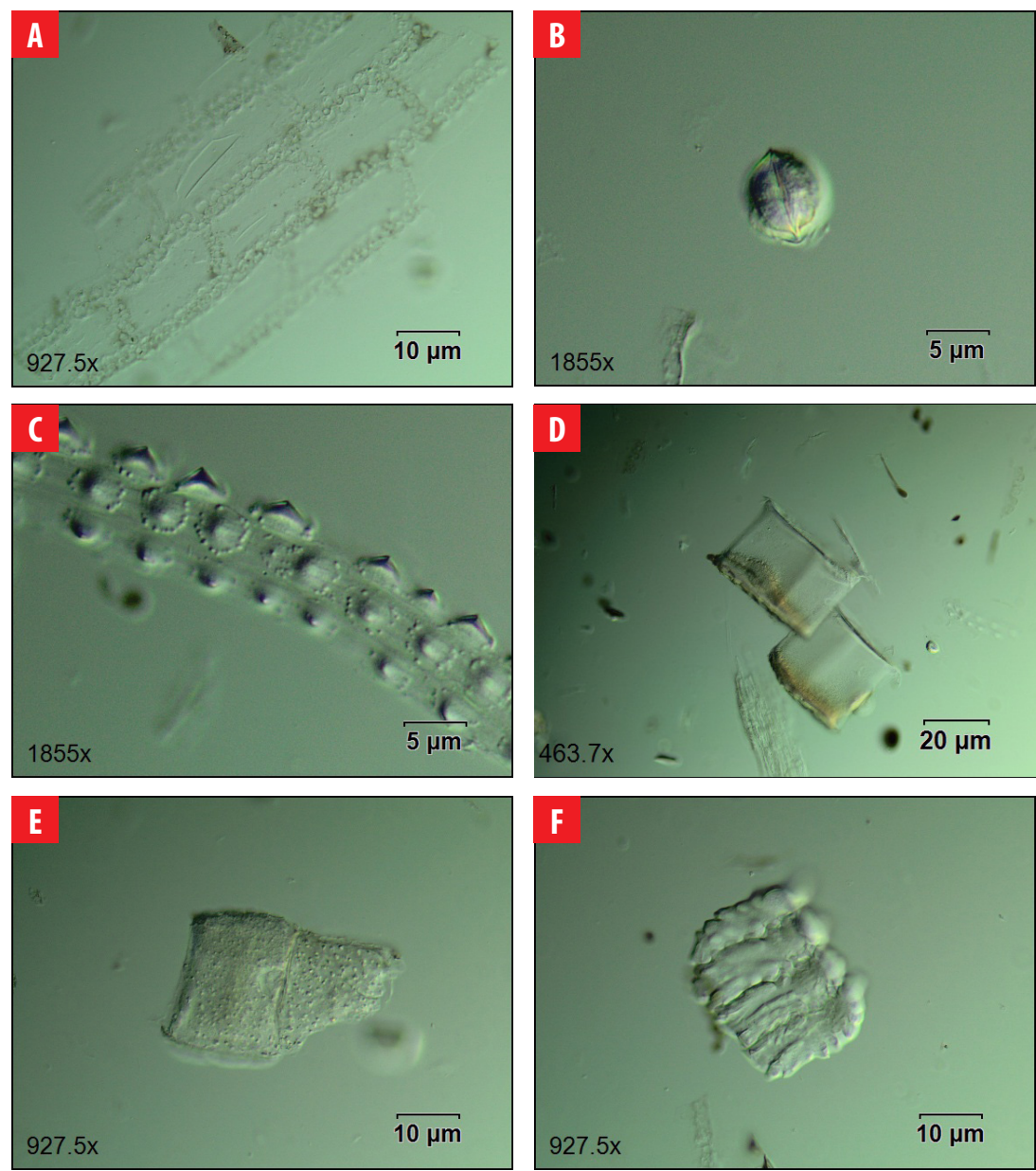


\subsection{Cyperaceae. Scleria melaleuca Rchb. Ex Schltdl. \& Cham.}

\section{Common name: Cortadera}

Origin: Native (Indigenous taxon)

Part Processed: Leaf, stem

Density: High

Morphotypes: (A) Acicular equal prickle; (B) elongate echinate long cell; (C) epidermal phytoliths; (D) ovate phytoliths; (E \& F) papillae cells
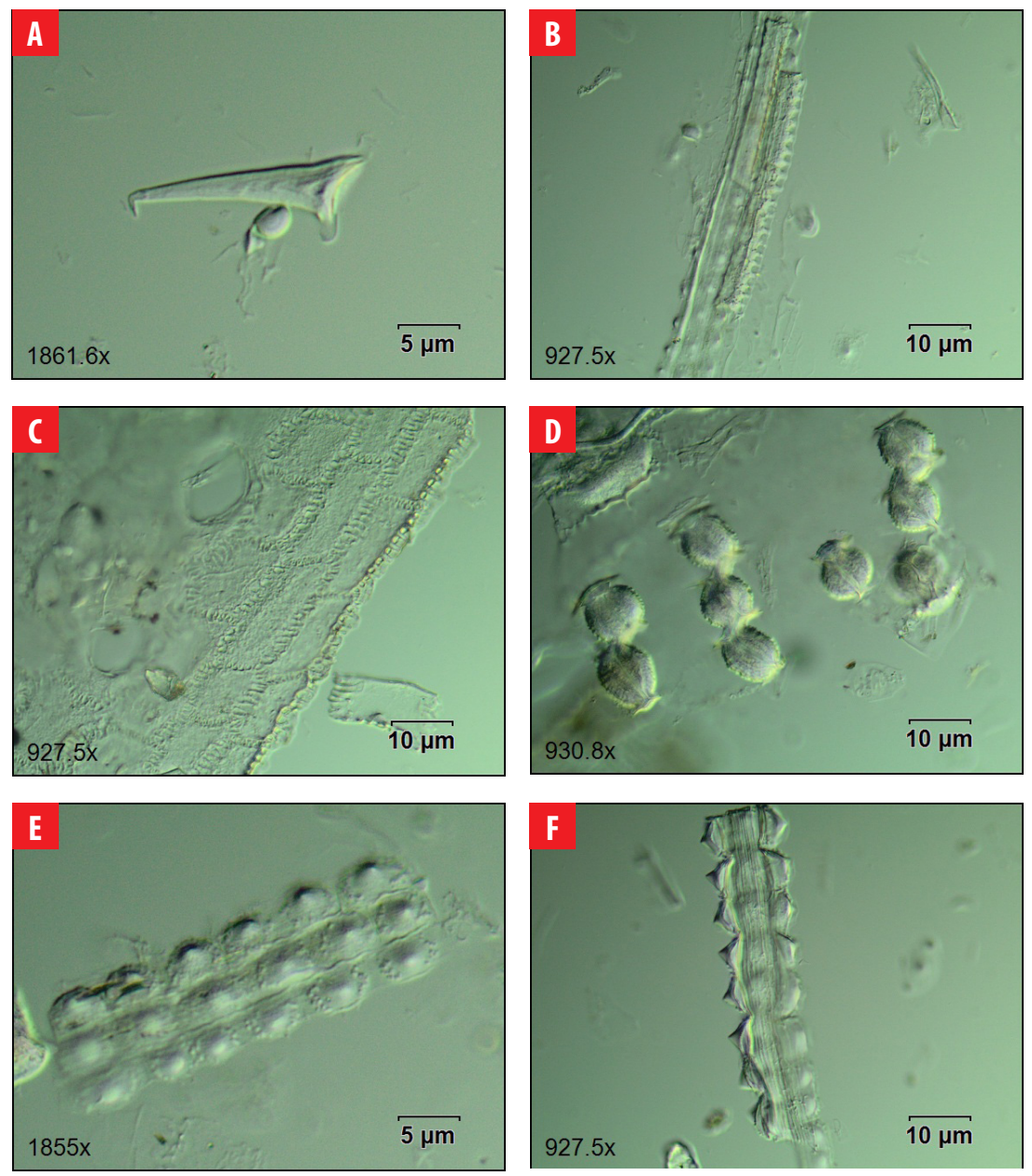
4.9 Euphorbiaceae. Aleurites moluccana (L.) Willd.

Common name: Candlenut / Tocte

Origin: Introduced (Cultivated)

Part Processed: Leaf, stem, wood

Density: Low

Morphotypes: Mesophyll epidermal phytoliths
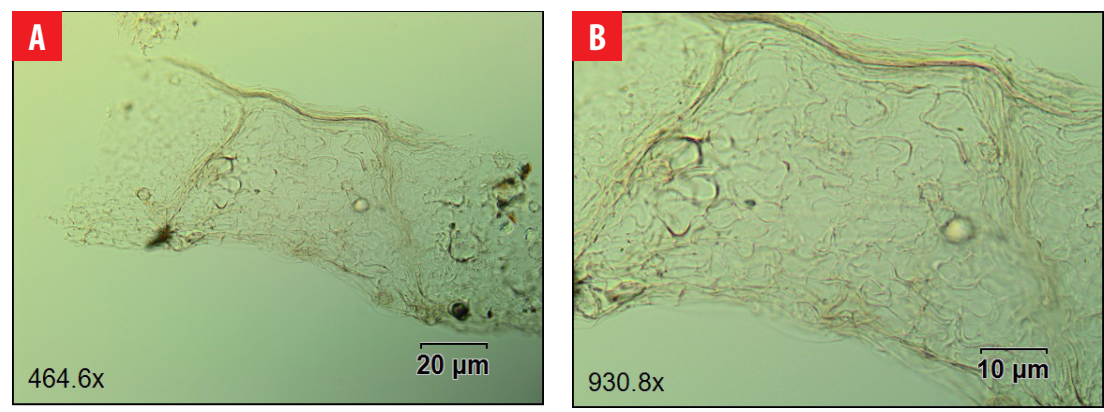

4.10 Euphorbiaceae. Hippomane mancinella $\mathrm{L}$.

Common name: Poison apple / Manzanillo

Origin: Native (Indigenous taxon)

Part Processed: Leaf, stem, wood

Density: LoW

Morphotypes: Mesophyll epidermal phytoliths
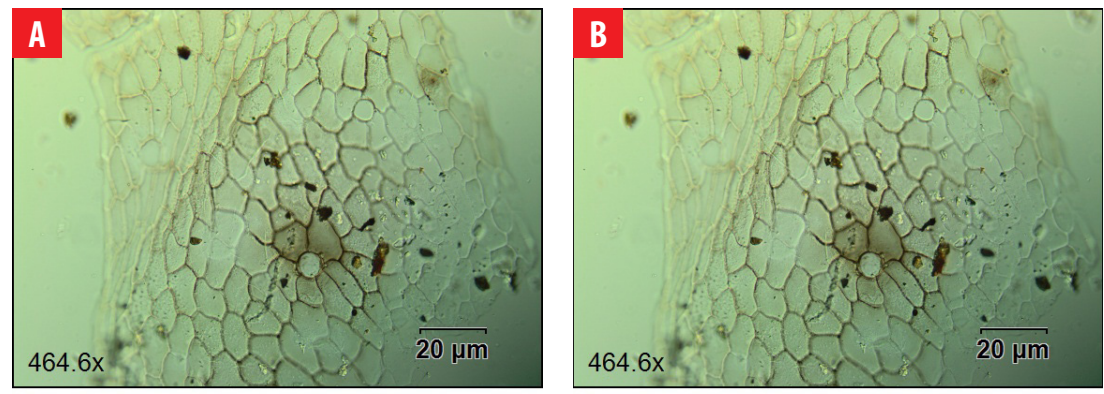
4.11 Fabaceae. Piscidia carthagenensis Jacq.

Common name: Piscidia/ Matazarno

Origin: Native (Indigenous taxon)

Part Processed: Leaf, stem

Density: LoW

Morphotypes: (A) Fusiform equal; (B) globular sinuate; (C) hair base; (D) irregular equal; (E) mesophyll phytoliths; (F) polyhedral phytoliths
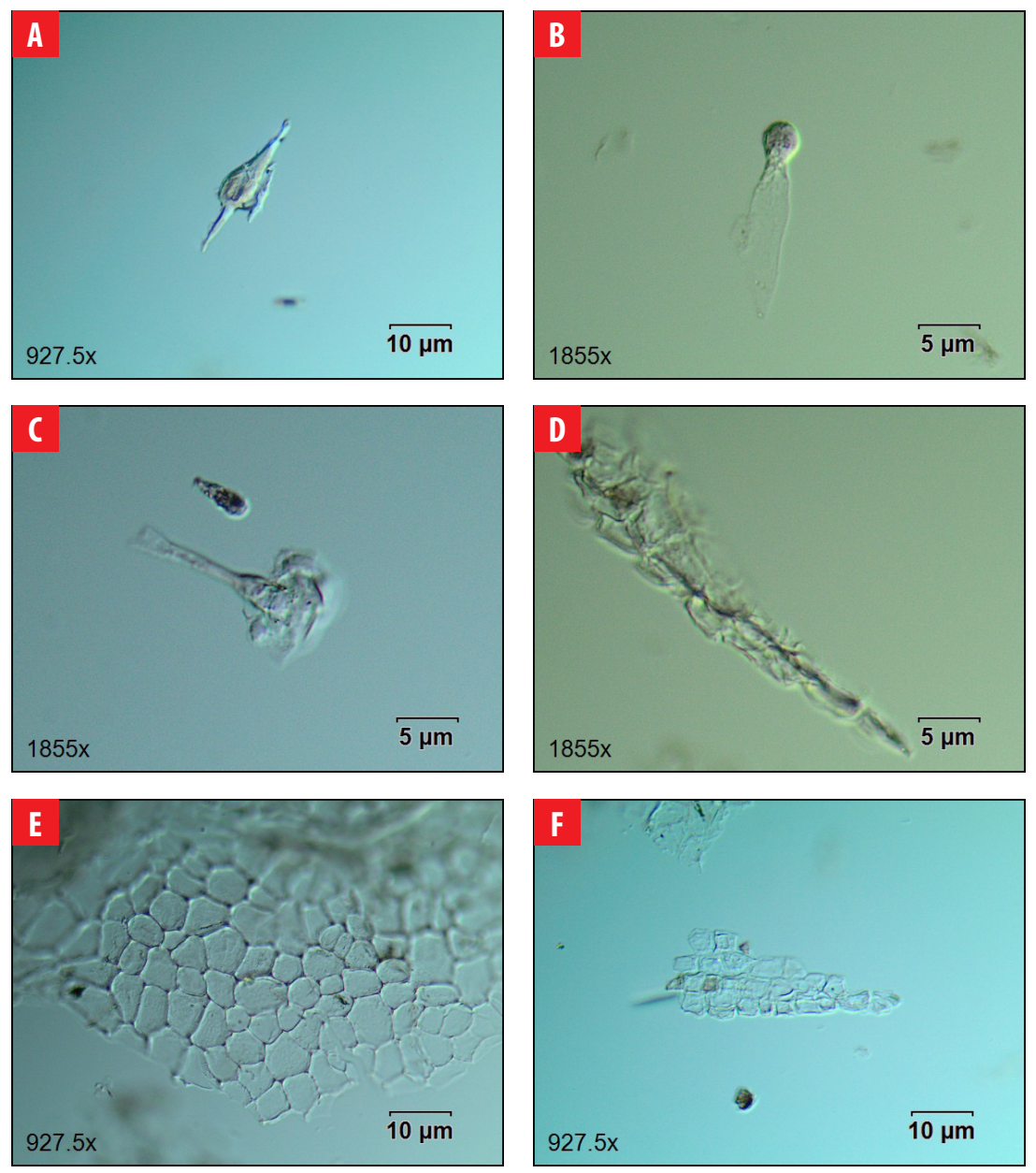


\subsection{Lauraceae. Persea americana Mill.}

Common name: Avocado / Aguacate

Origin: Introduced (Cultivated)

Part Processed: Leaf, stem

Density: Low

Morphotypes: (A) Cylindrical sulcate tracheid; (B - D) globular sinuate phytoliths; (E \& F) mesophyll epidermal phytoliths
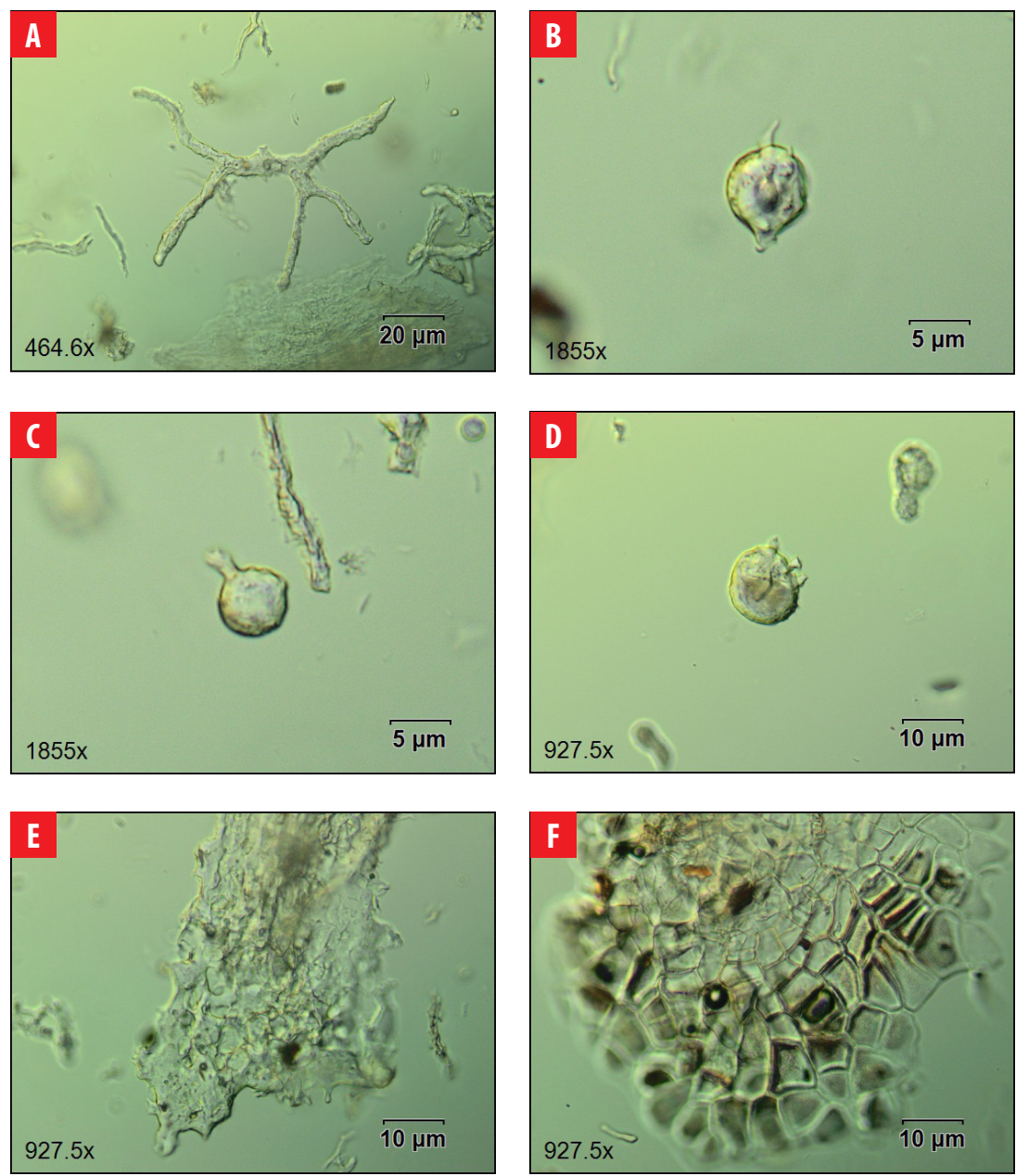
4.13 Malvaceae. Gossypium darwinii G. Watt.

Common name: Galápagos Cotton / Algodón de Galápagos

Origin: Endemic

Part Processed: Leaf, stem, wood

Density: Low

Morphotypes: Acicular hair cell
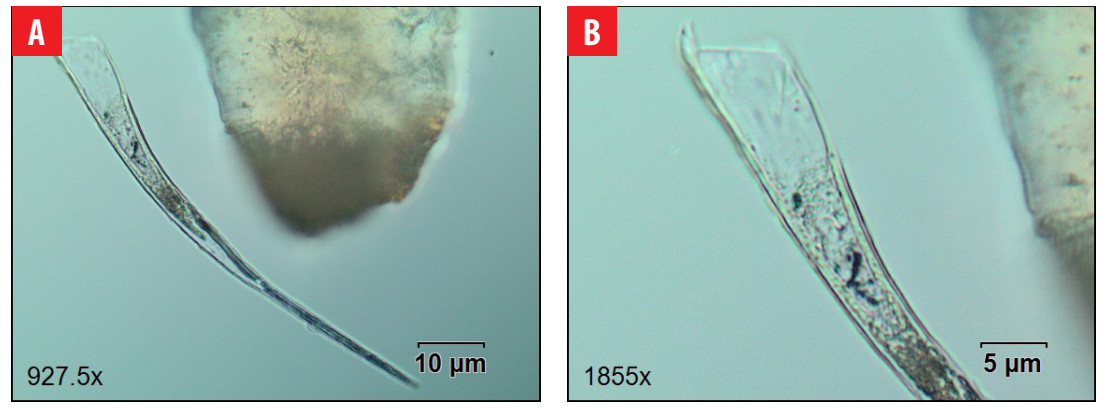

4.14 Malvaceae. Miconia robinsoniana Cogn.

Common name: Miconia

Origin: Endemic

Part Processed: Leaf, stem, flowers

Density: Low

Morphotypes: Globular piscilate phytoliths from flowers
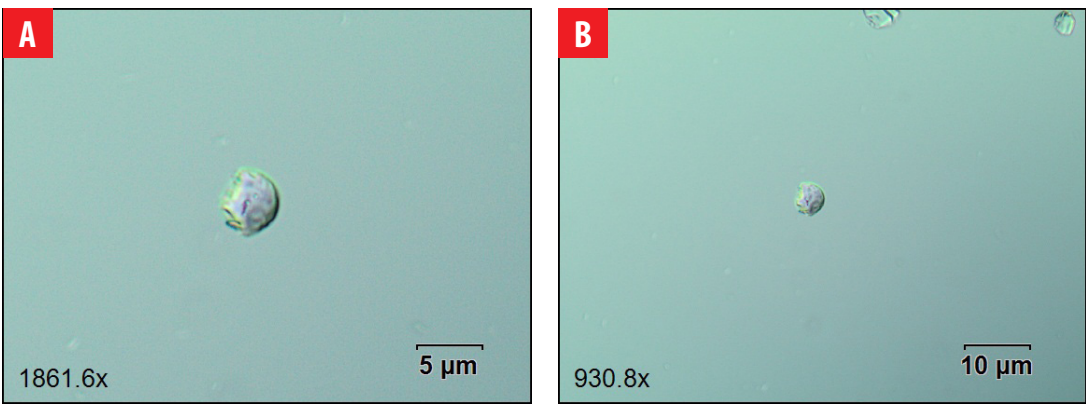


\subsection{Moraceae. Artocarpus altilis (Parkinson) Fosberg}

Common name: Breadfruit / Frutipan

Origin: Introduced (Cultivated)

Part Processed: Leaf and stem

Density: High

Morphotypes: (A) Acicular columellate hair cell; (B) acicular hair cell; (C) cylindrical sulcate tracheid; (D \& E) hair base; (F) mesophyll epidermal phytoliths
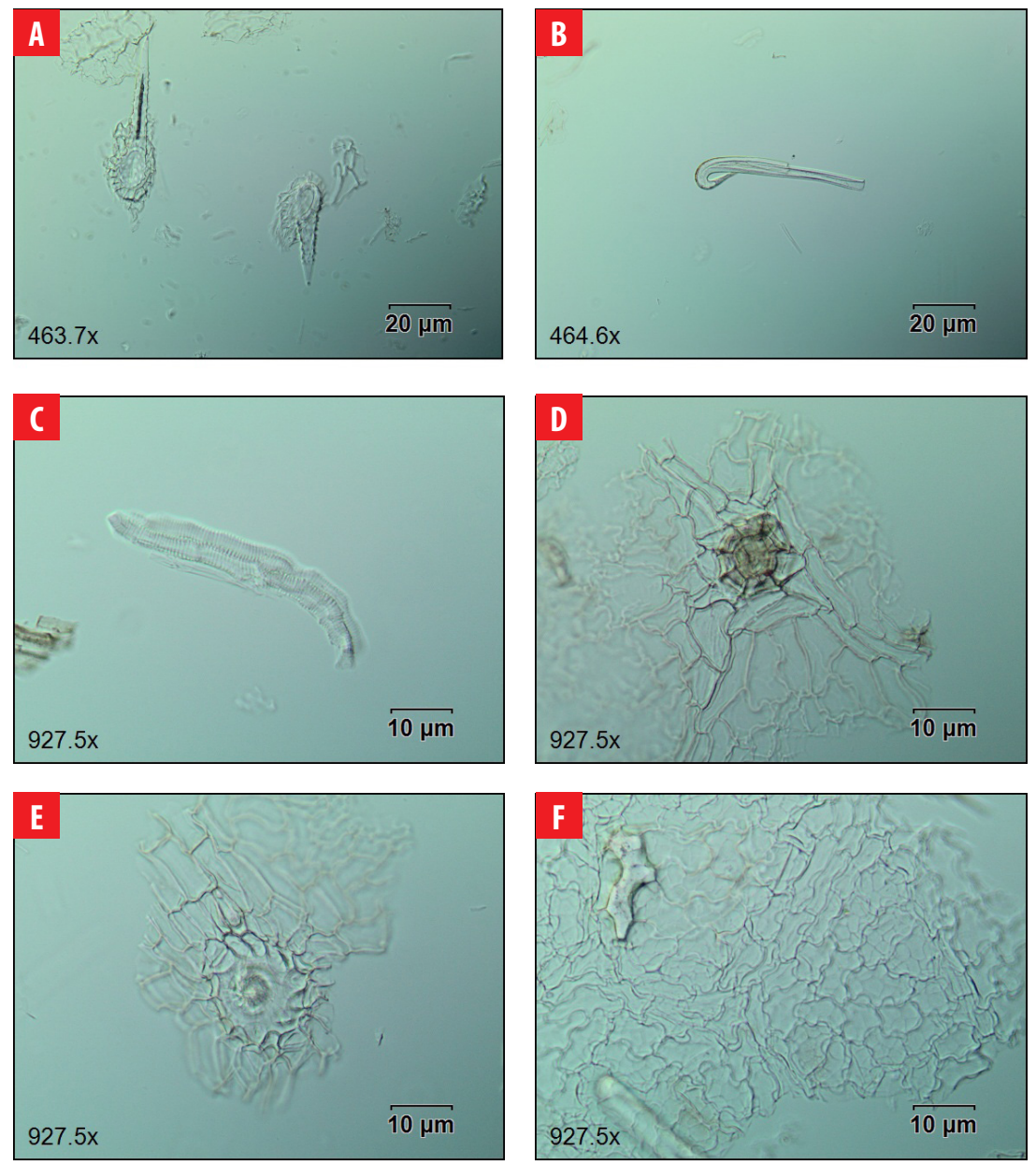


\subsection{Myrtaceae. Psidium galapageium var. howellii Porter}

Common name: Guayabillo/ Galápagos guava

Origin: Endemic

Part Processed: Leaf, stem

Density: LoW

Morphotypes: (A) Elliptical rugulate; (B) globular sinuate; (C) hair base; (D) ovate equal; (E) polyhedral phytoliths; (F) stellate linear
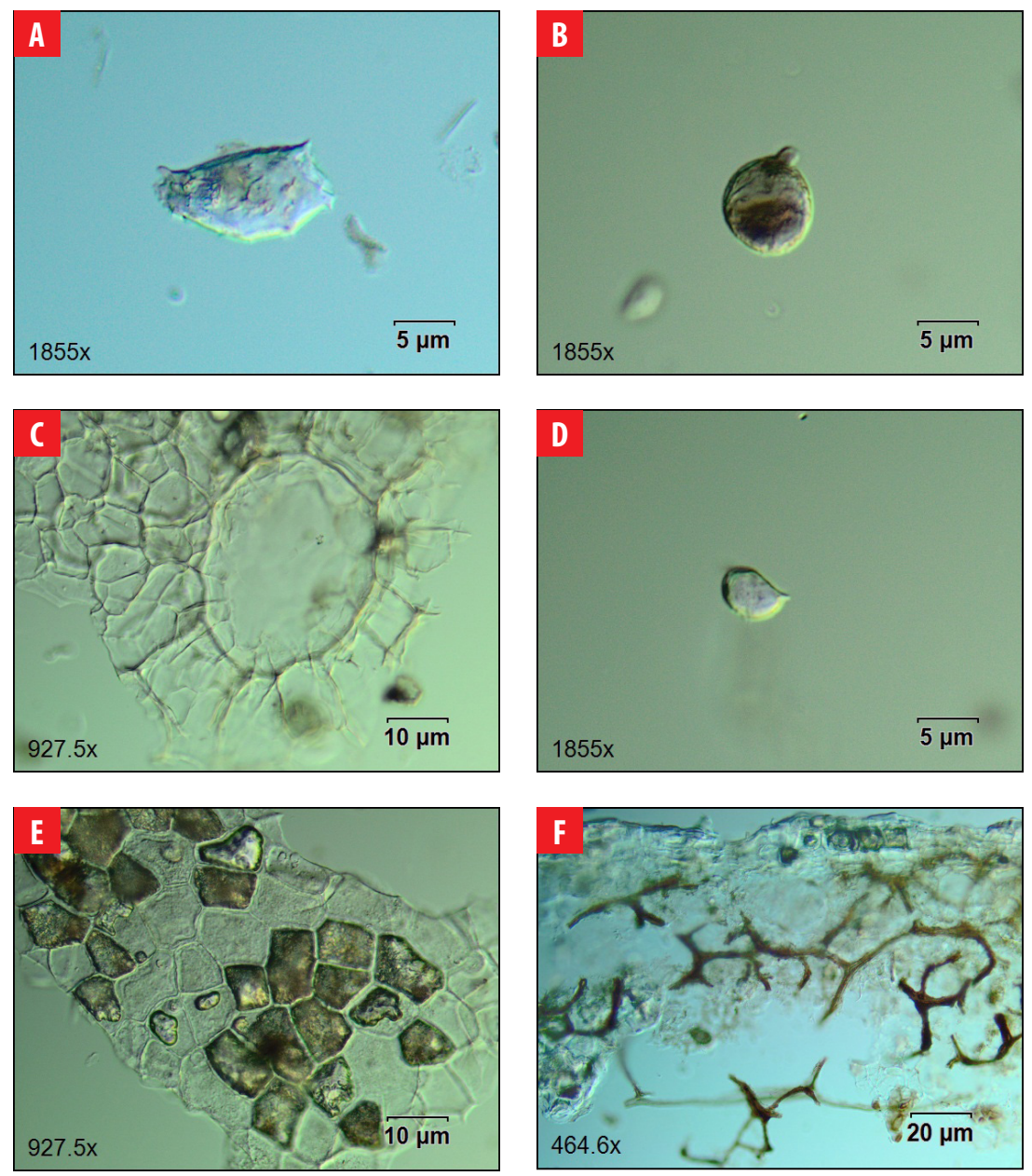


\subsection{Myrtaceae. Syzygium jambos (L.) Alston.}

Common name: Plum rose / Pomarosa

Origin: Introduced (Escaped)

Part Processed: Leaf, stem

Density: Low

Morphotypes: (A) Carinate facetate bulliform; (B) clavate facetate; (C) cylindric sulcate tracheid; (D) globular sinuate; (E) polyhedral phytoliths; (F) stellate psilate bulliform cell
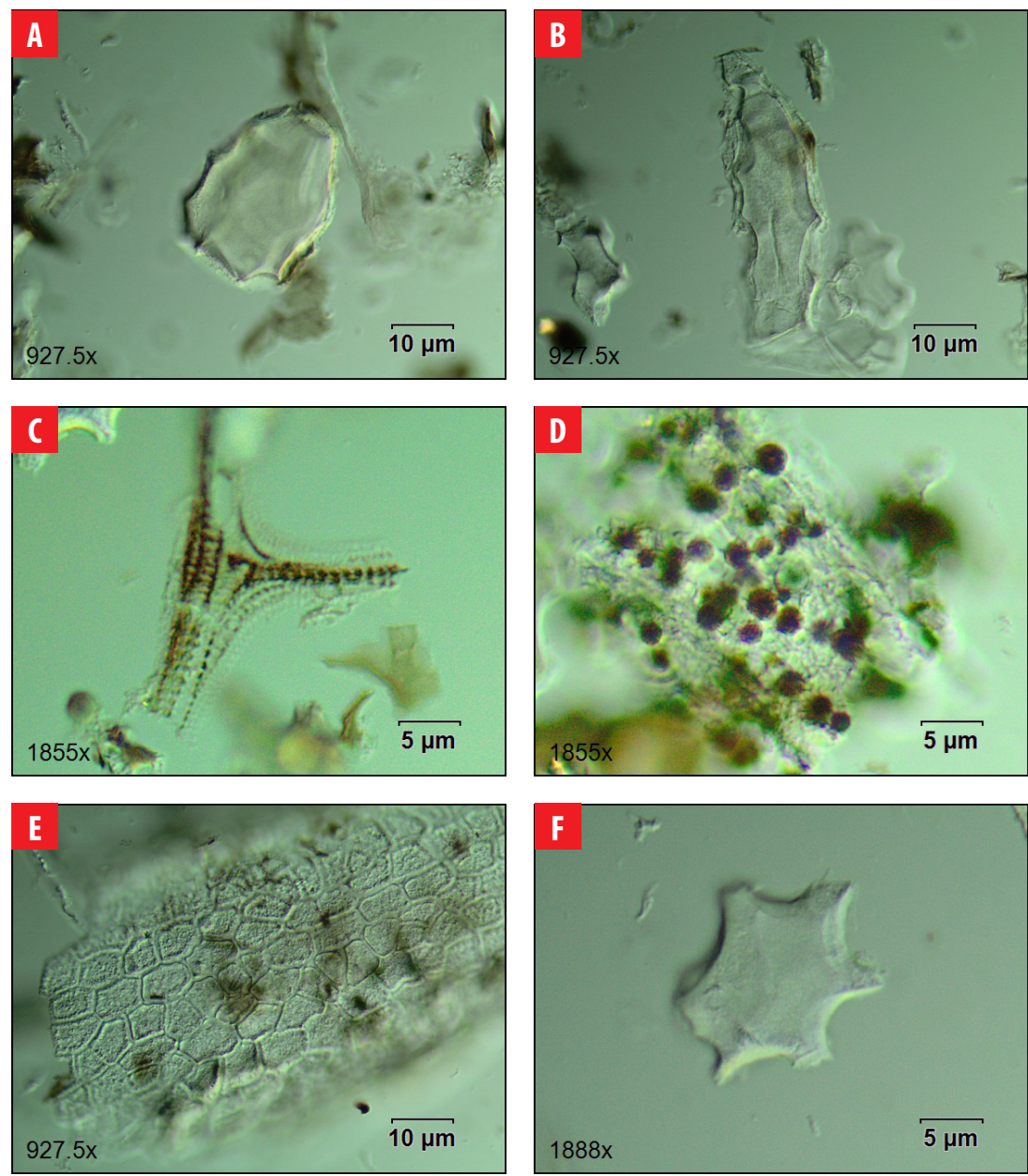


\subsection{Myrtaceae. Psidium guajava L.}

Common name: Common guava / Guayaba

Origin: Introduced (Cultivated)

Part Processed: Leaf, stem

Density: LoW

Morphotypes: (A) Elongate cylindrical; (B - D) polyhedral phytoliths
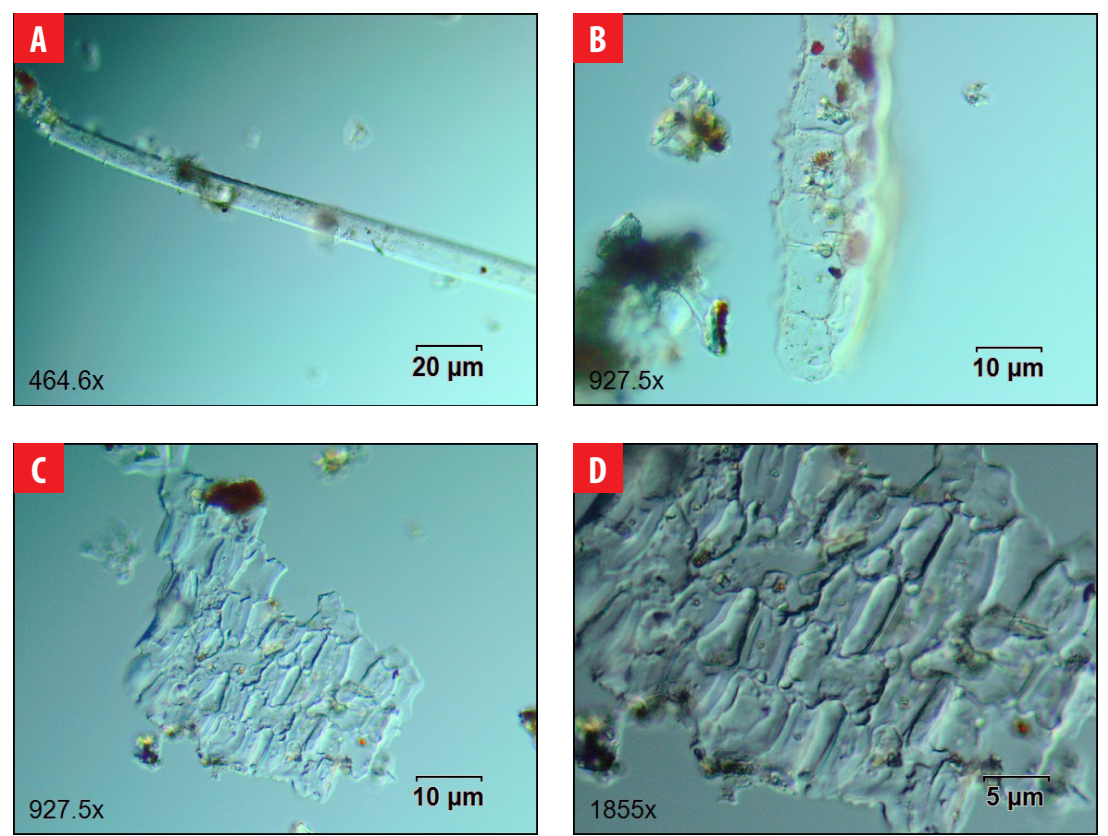
4.19 Poaceae. Bambusa vulgaris var. vittata Rivière \& C. Rivière

Common name: Bamboo

Origin: Introduced (Cultivated)

Part Processed: Leaf, stem

Density: High

Morphotypes: (A) Cuneiform bulliform cell; (B \& C) parallepipedal bulliform cell; (D) saddle epidermal short cells; (E) saddle short cell and stomatal phytoliths
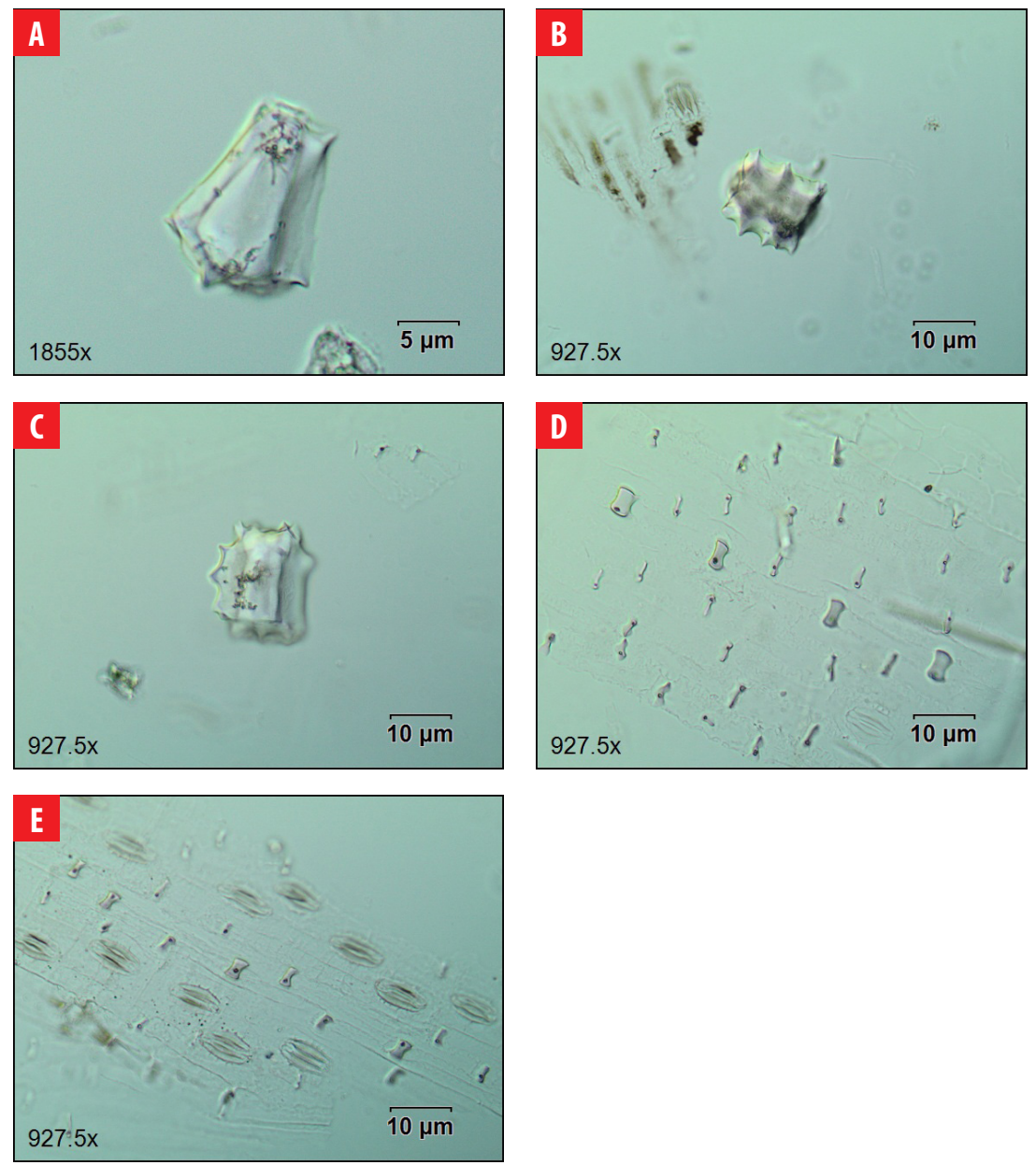


\subsection{Poaceae. Bambusa vulgaris var. vulgaris Schrad ex Wendle}

Common name: Bamboo / Caña verde, Caña Guadua

Origin: Introduced (Cultivated)

Part Processed: Leaf, stem

Density: High

Morphotypes: (A) Cuneiform bulliform cell; (B \& C) parallepipedal bulliform cell; (D - F) saddle epidermal short cells
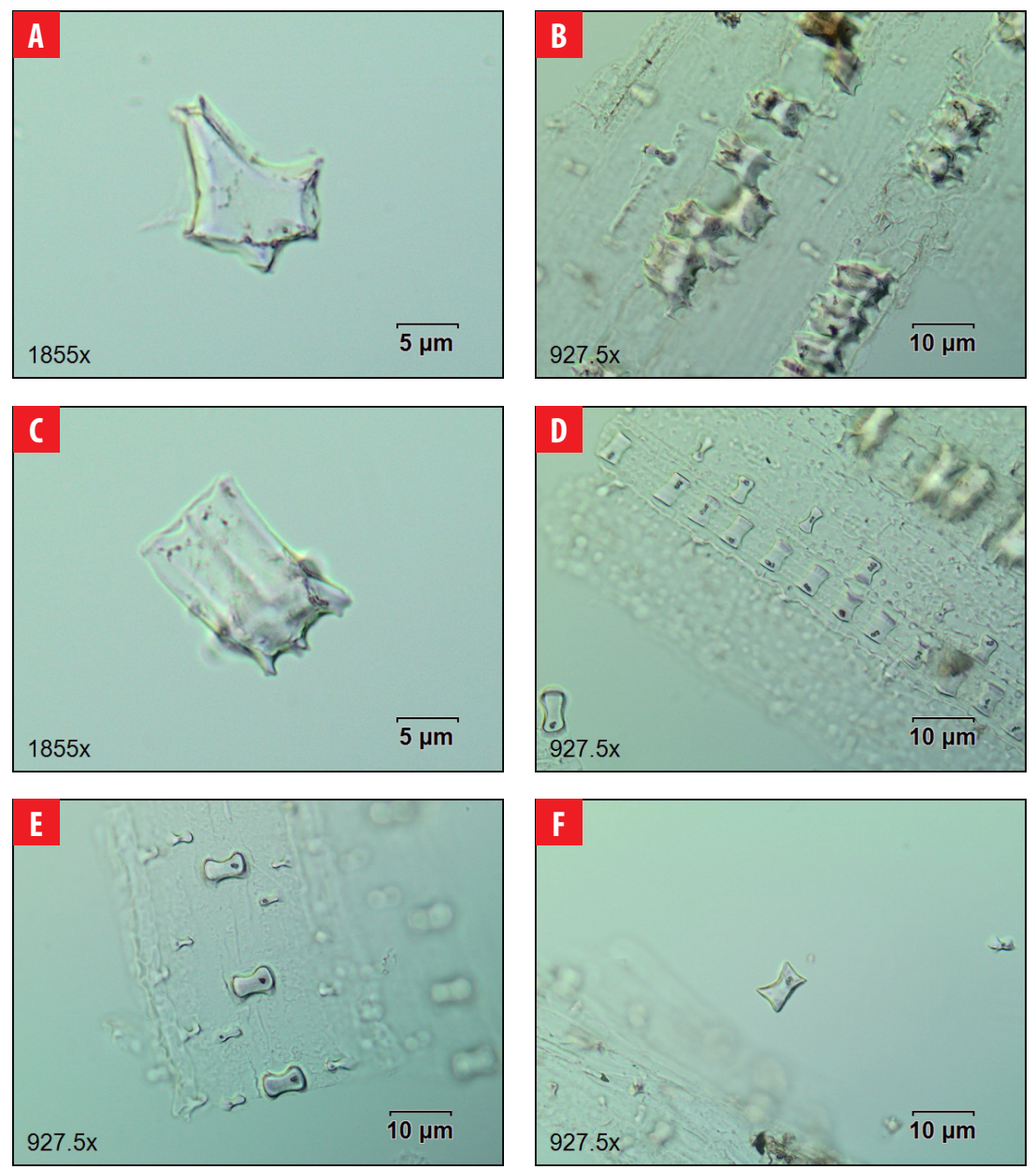


\subsection{Poaceae. Brachiaria decumbens Stapf.}

Common name: Signalgrass / Pasto Brachiaria

Origin: Introduced (Escaped)

Part Processed: Leaf, flowers

Density: High

Morphotypes: (A) Scutiform lanceolate; (B - E) variants of bilobate concave outer margins short shaft; (F) cuneiform bulliform cell
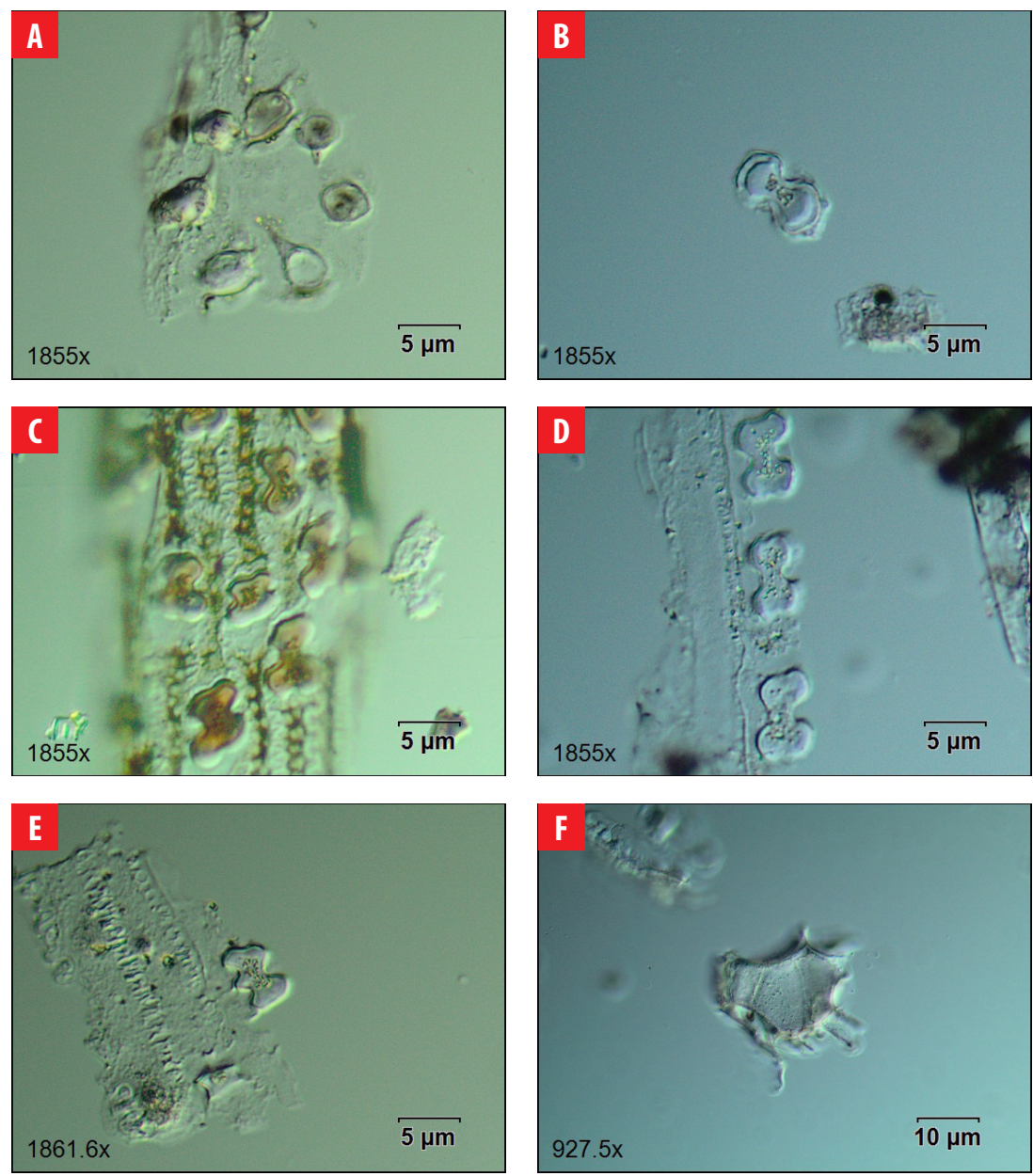
Morphotypes continued: (G) Glume phytoliths; (H) polylobate epidermal short cell; (I) saddle short cell; (J) stomatal phytoliths,
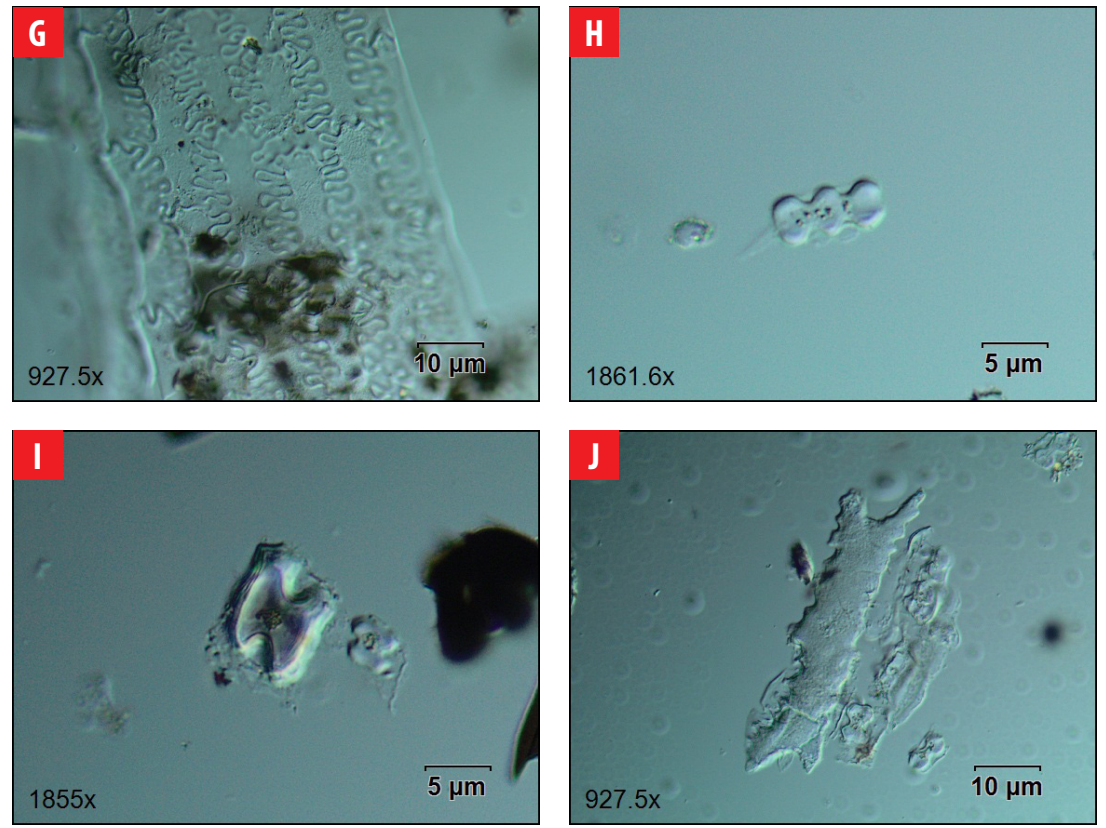


\subsection{Poaceae. Cynodon nlemfuensis Vanderyst.}

Common name: African bermudagrass / Pasto Estrella

Origin: Introduced (Accidentally)

Part Processed: Leaf

Density: High

Morphotypes: (A) Cuneiform bulliform cell; (B) elongate cylindrical psilate; (C) polyhedral epidermal phytoliths; (D \& E) saddle epidermal short cell
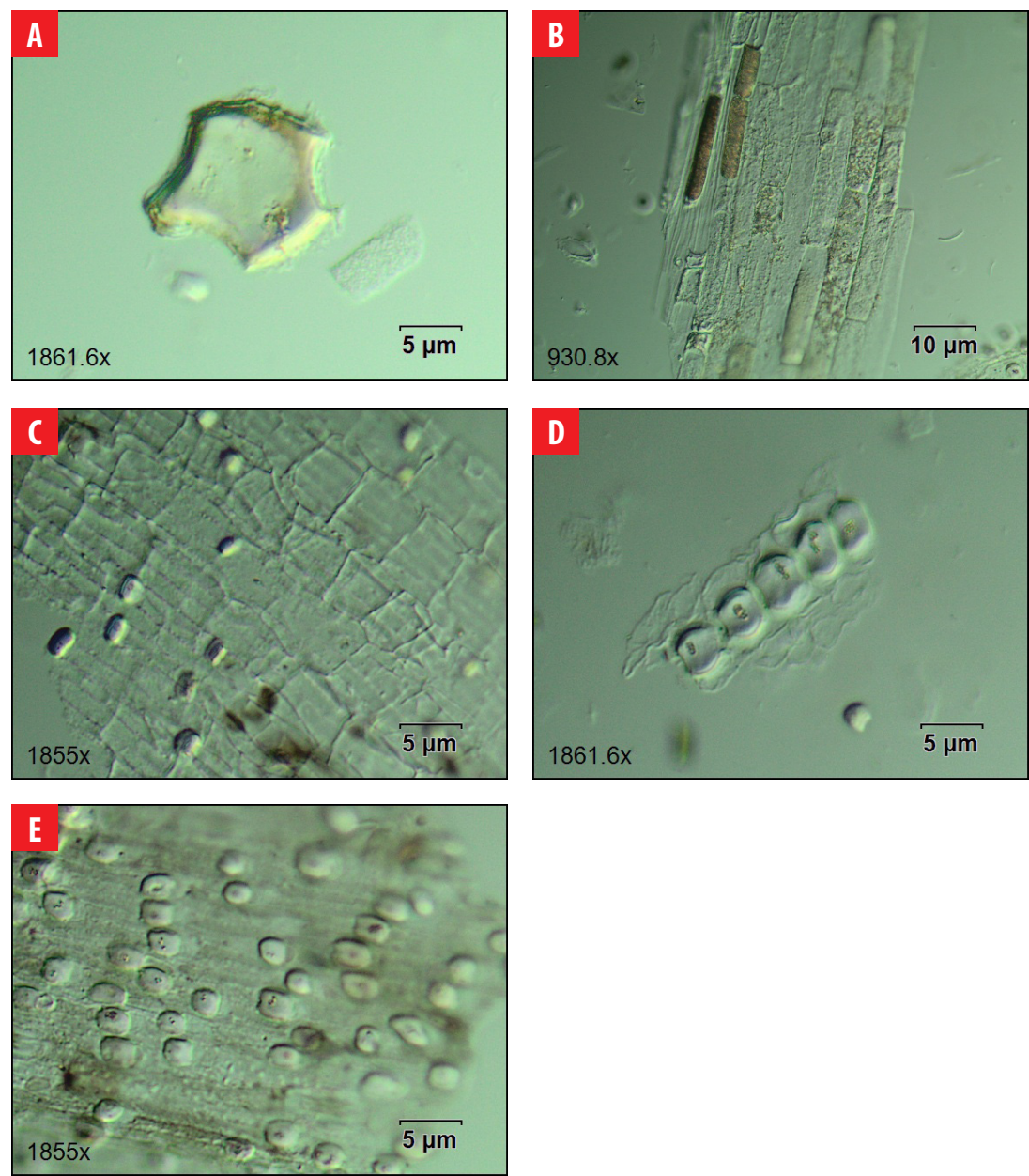


\subsection{Poaceae. Digitaria sp.}

Origin: Introduced (Accidentally)

Part Processed: Leaf, flower

Density: High

Morphotypes: (A) Scutiform lanceolate; (B) bilobate concave outer margins long shaft; $(\mathbf{C}-\mathbf{F})$ variants of bilobate concave outer margins short shaft
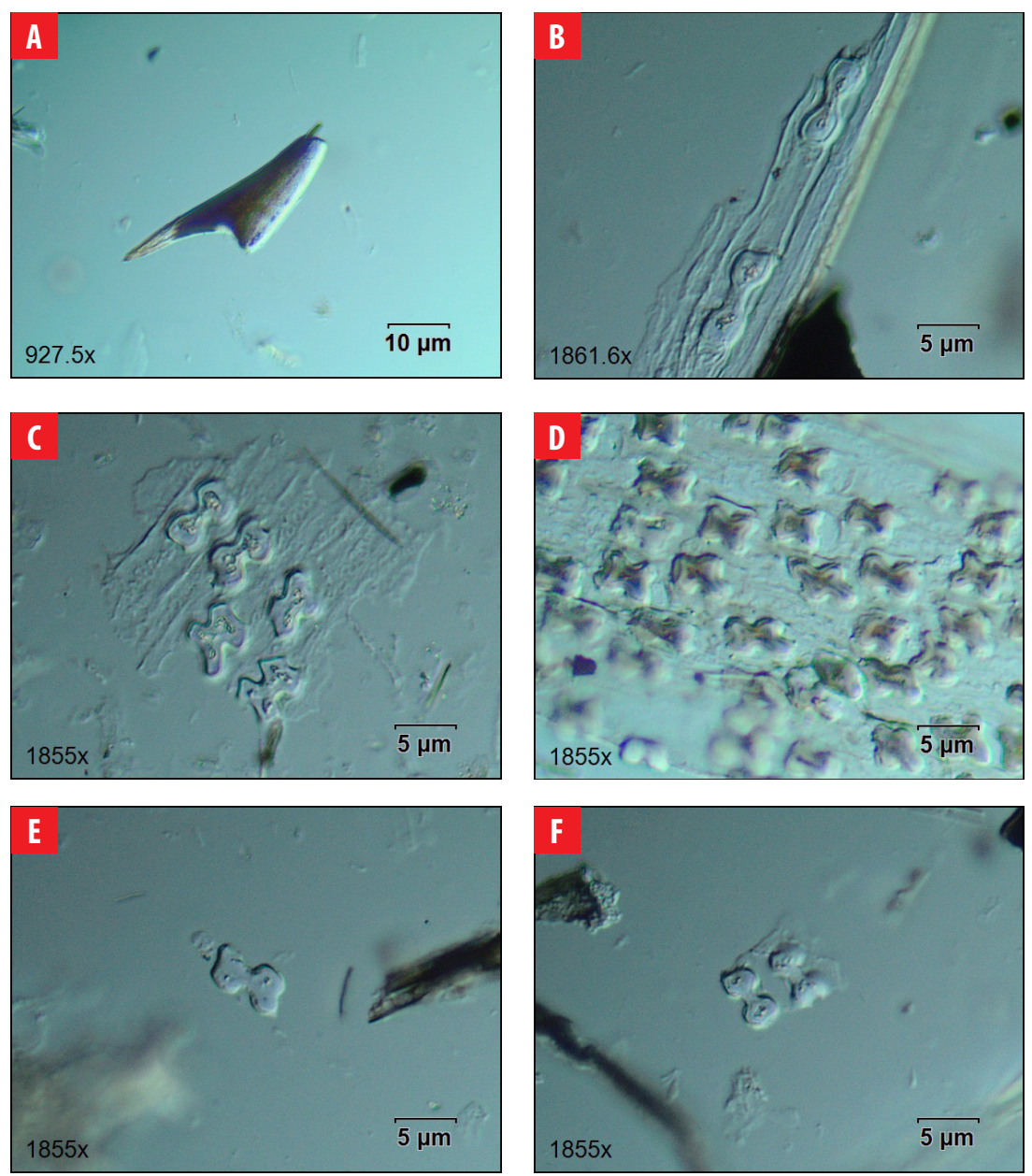
Morphotypes continued: (G) Bilobate concave outer margins short shaft; (H) epidermal aggregation; (I) papillae cells.
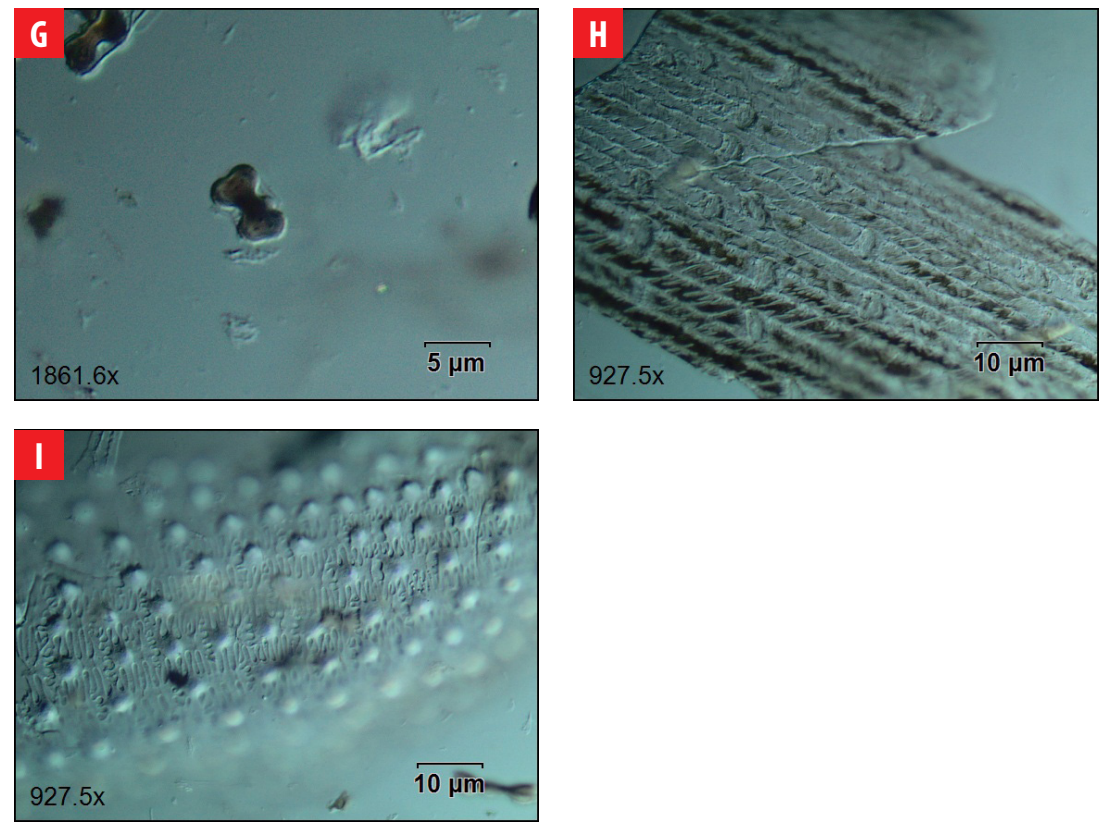


\subsection{Poaceae. cf. Eleusine indica (L.) Gaertn.}

Common name: Crowfoot grass

Origin: Introduced (Accidental)

Part Processed: Leaf, flower

Density: High

Morphotypes: (A) Scutiform lanceolate; (B) elongate echinate long cell; (C) epidermal tissue; (D) quadra-lobate short cell; (E) saddle epidermal short cell; (F) stomatal phytoliths
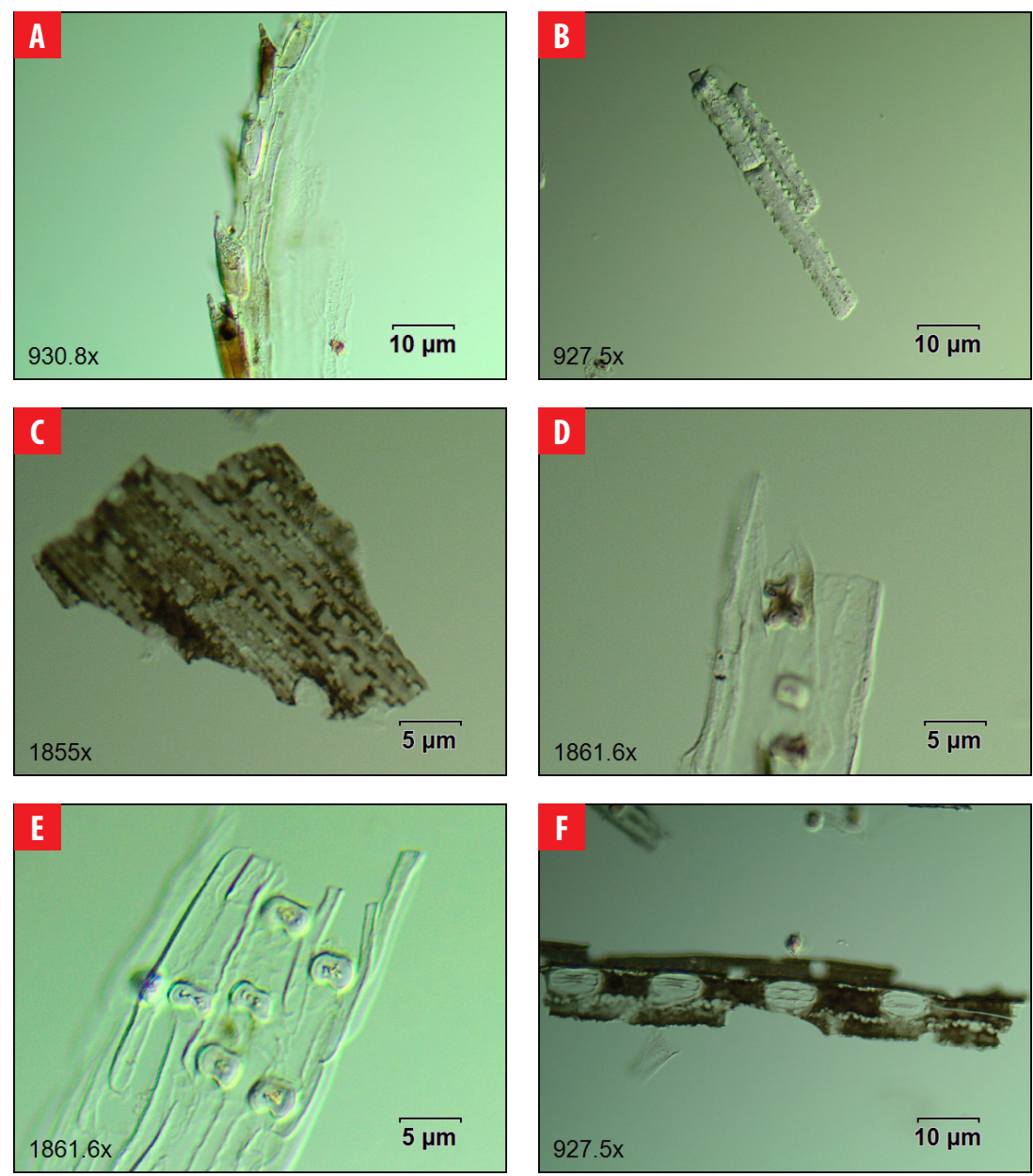


\subsection{Poaceae. Eragrostis amabilis (L.) Wight \& Arn. ex Nees}

Common name: Japanese love-grass / Capim plumoso

Origin: Introduced (Accidental)

Part Processed: Leaf, flower

Density: High

Morphotypes: (A) Scutiform lanceolate; (B) bilobate concave outer margins short shaft; (C) elongate echinate long cell; (D) parallepipedal bulliform cell; (E) polylobate epidermal short cell; (F) quadra-lobate epidermal short cell
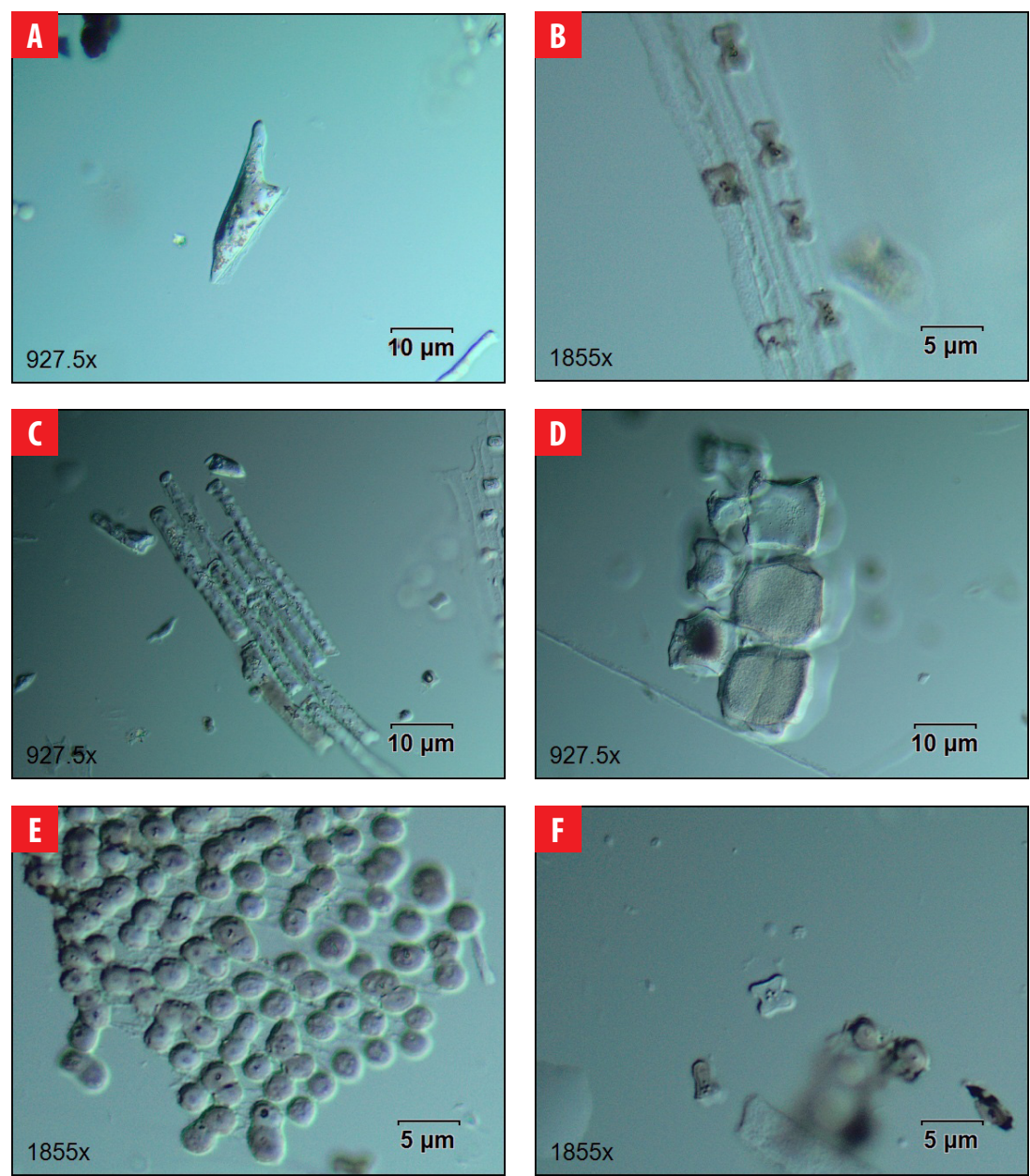
Morphotypes continued: (G) rondel tall pyramidal ovate top; (H) collapsed saddle; (I) stomatal and rondel short cells
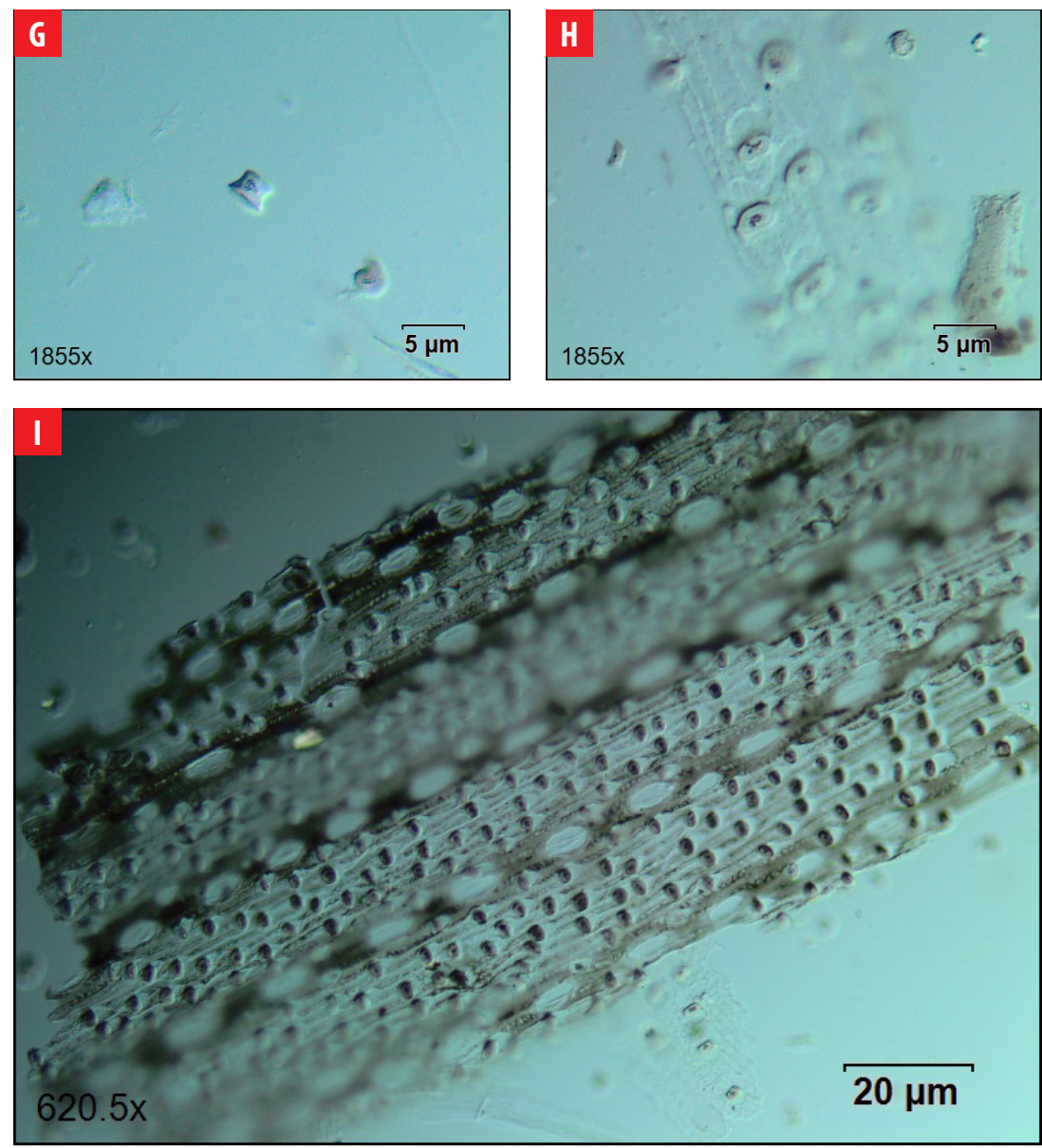


\subsection{Poaceae. Panicum sp.}

Common name: Guinea grass / Pasto Sabolla

Origin: Introduced (Escaped)

Part Processed: Leaf, flower

Density: High

Morphotypes: (A-E) variants of bilobate concave outer margin short shaft; (F) cuneiform bulliform cell.
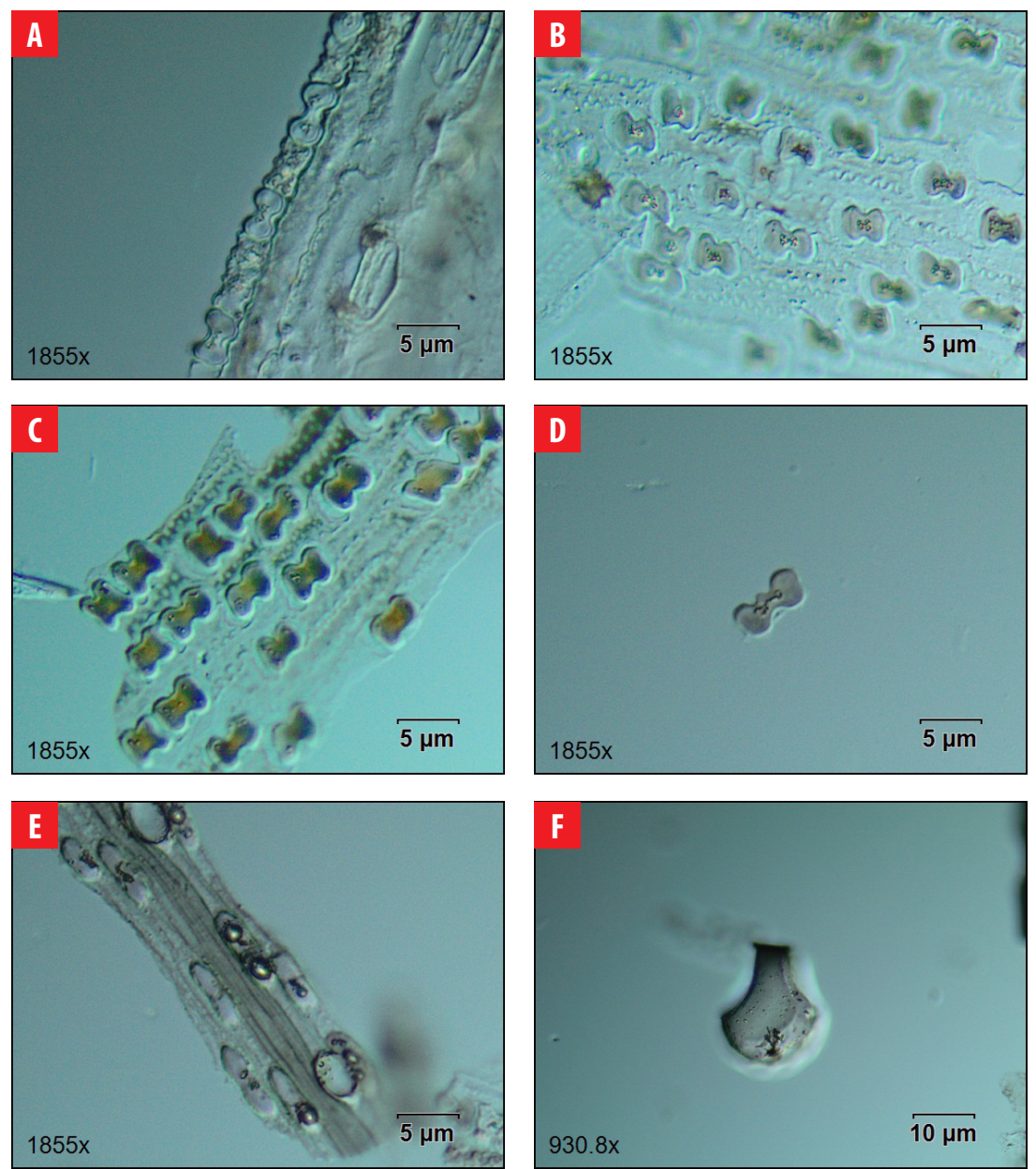
Morphotypes continued: (G) glume phytoliths; (H) parallepipedal billuform cell; (I) polylobate epidermal short cell; (J) stomate phytoliths.
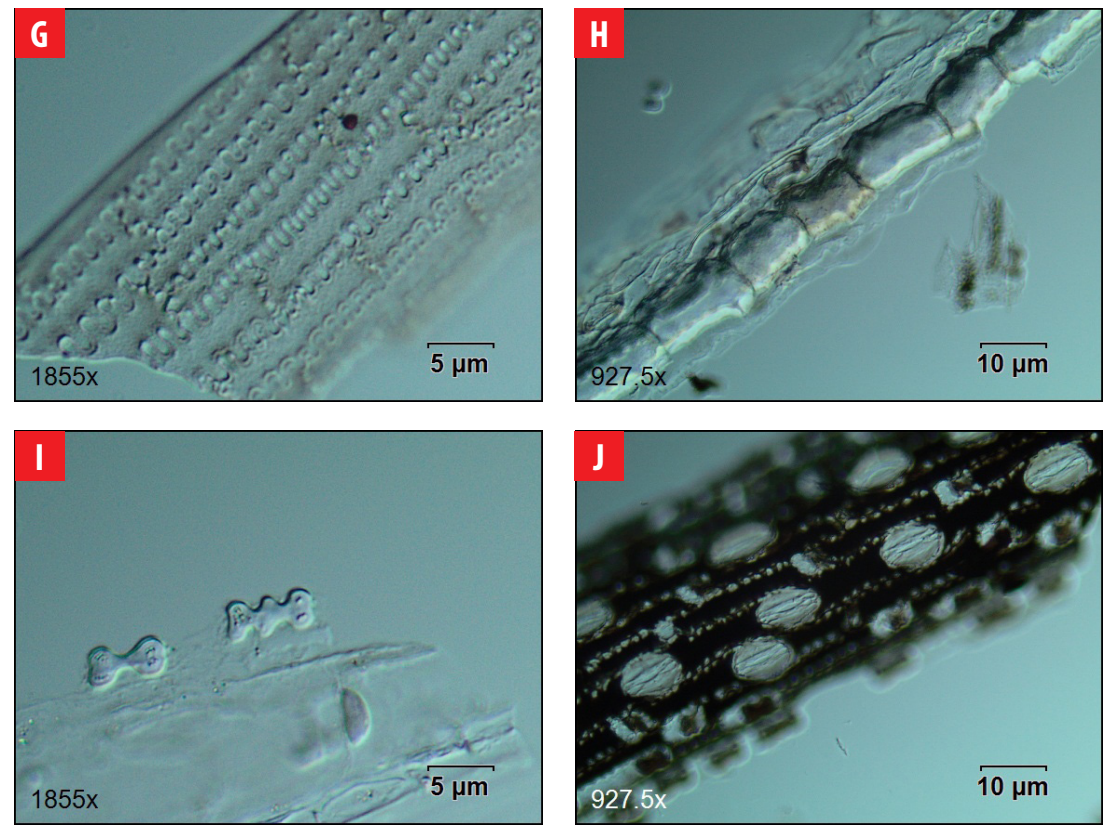


\subsection{Poaceae. Panicum maximum Jacq.}

Common name: Guinea grass / Pasto Tanzania

Origin: Introduced (Escaped)

Part Processed: Leaf, flower

Density: High

Morphotypes: (A) Acicular hair cell; (B-D) variants of bilobate concave outer margins short shaft; (E) glume phytoliths; (F) parallepipedal bulliform cell
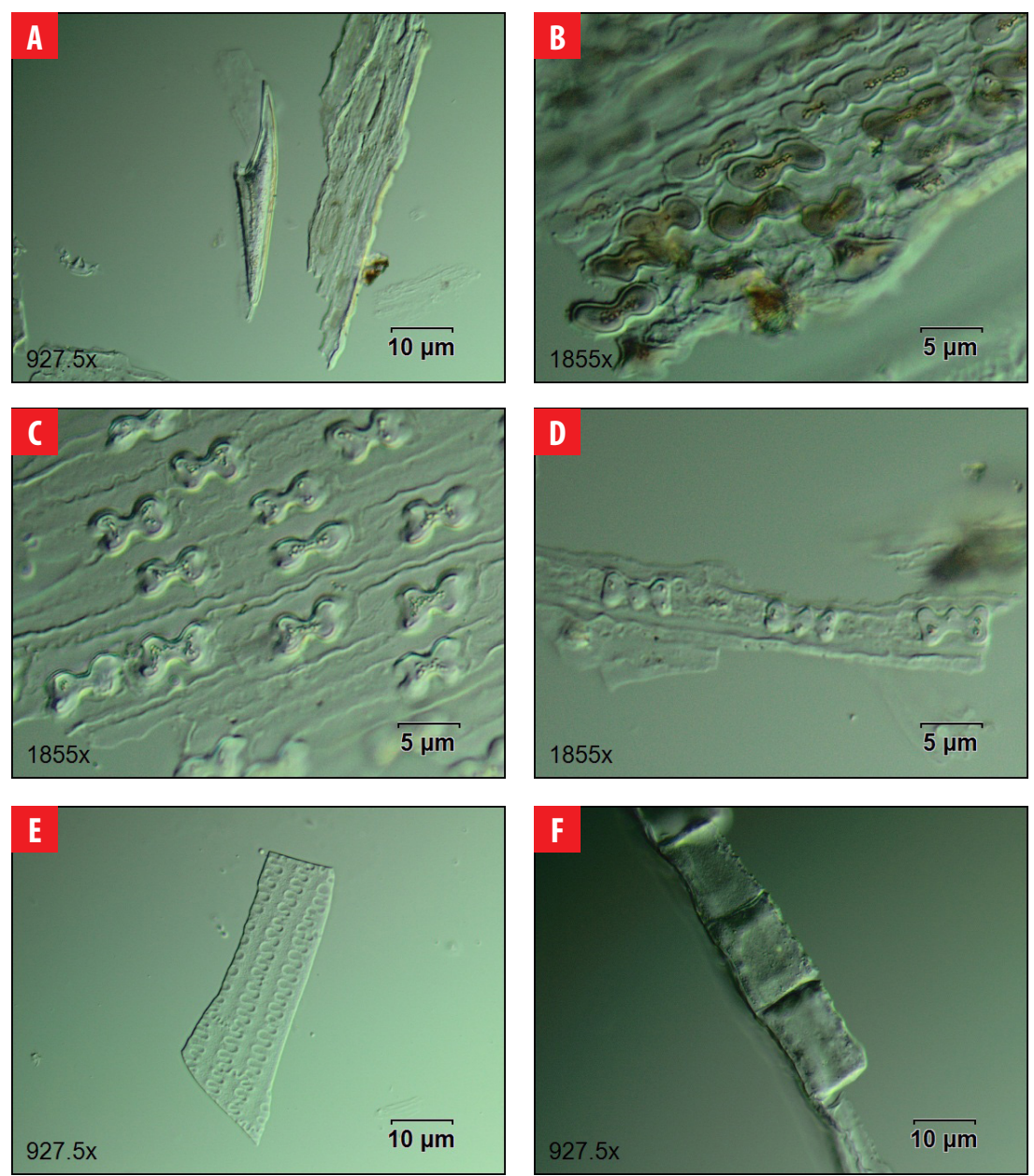
Morphotypes continued: (G) Polylobate epidermal short cell; (H) quadra-lobate epidermal short cell; (I \& J) stomate phytoliths.
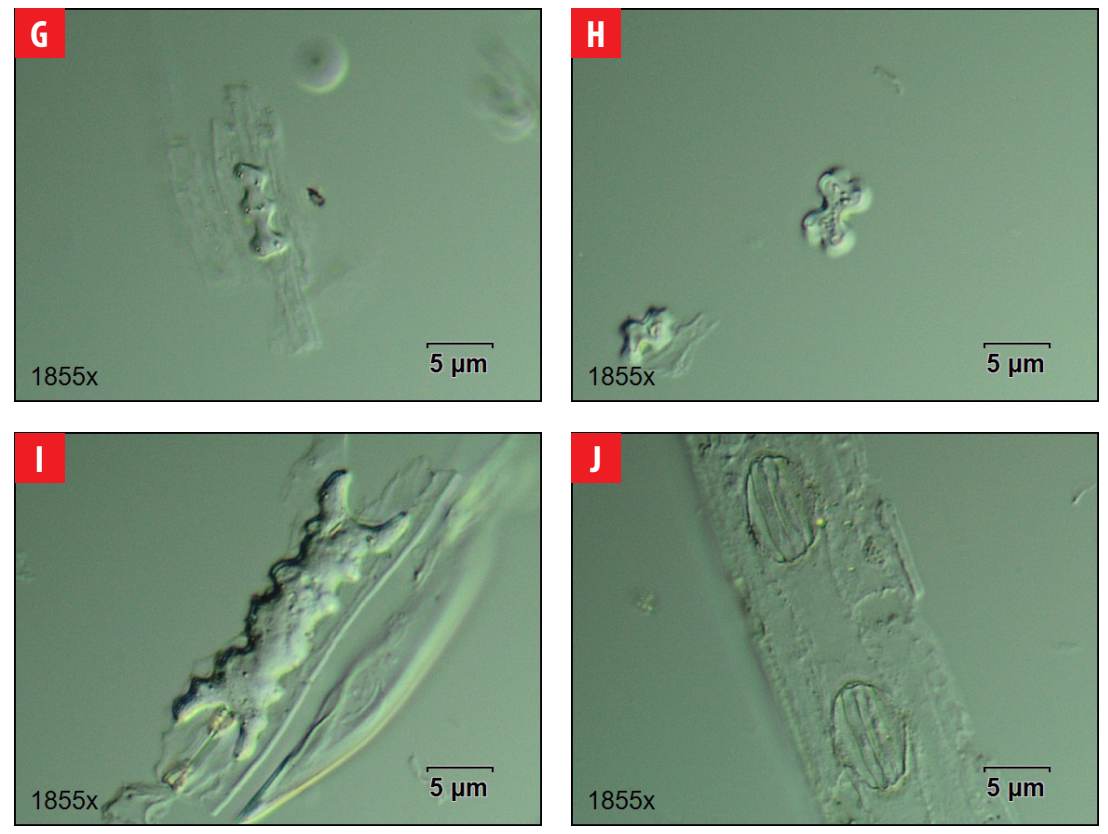


\subsection{Poaceae. Pennisetum purpureum Schum.}

Common name: Elephant grass / Pasto elefante

Origin: Introduced (Escaped)

Part Processed: Leaf, flower

Density: High

Morphotypes: (A) Scutiform lanceolate; (B \& C) variants of bilobate concave outer margin short shaft; (D) collapsed saddle; (E) elongate echinate; (F) glume phytoliths
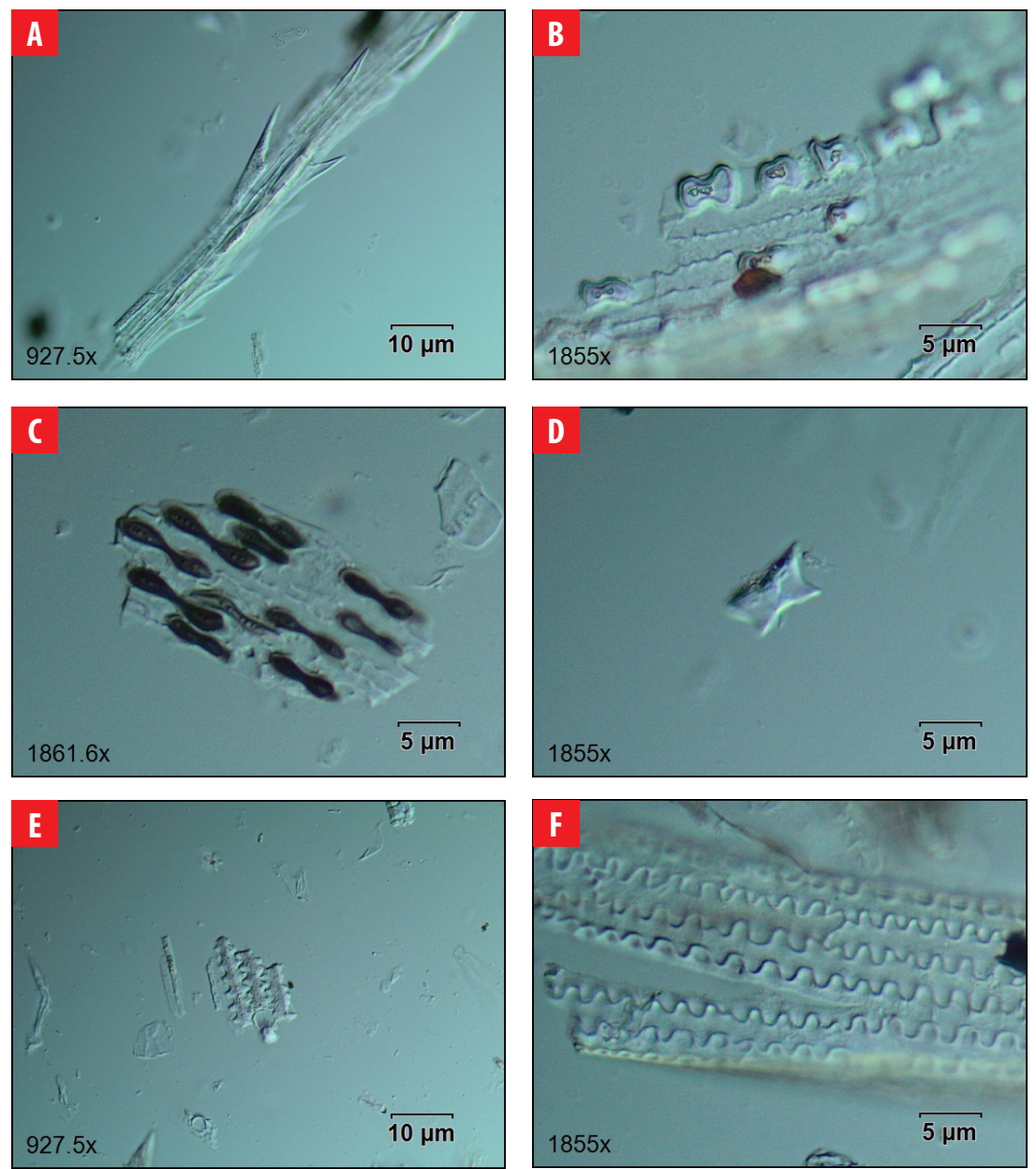
Morphotypes continued: (G) Rondel tall pyramidal ovate top; (H) stomatal phytoliths
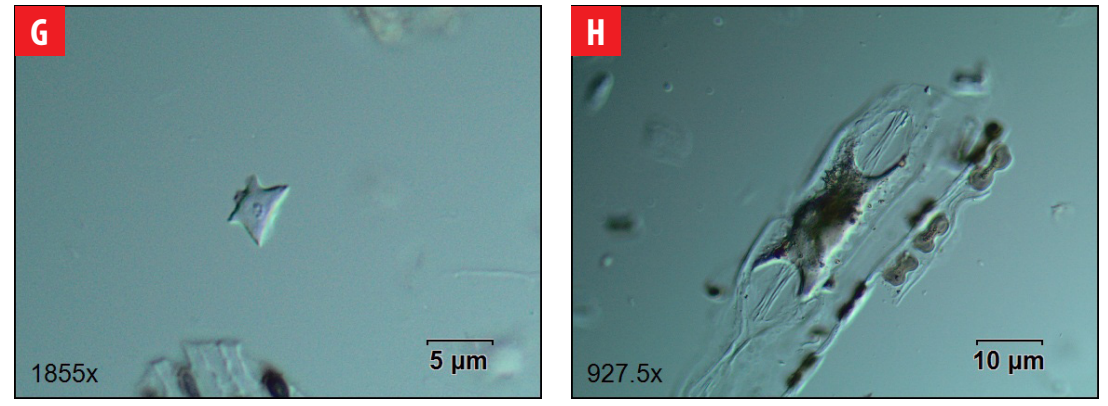


\subsection{Poaceae. Saccharum officinarum L.}

Common name: Sugarcane / Caña de Azúcar

Origin: Introduced (Cultivated)

Part Processed: Leaf

Density: High

Morphotypes: (A-C) Variants of bilobate concave outer margin short shaft; (D) elongate cylindrical psilate; (E) glum phytoliths; (F) mesophyll \& stomatal phytoliths
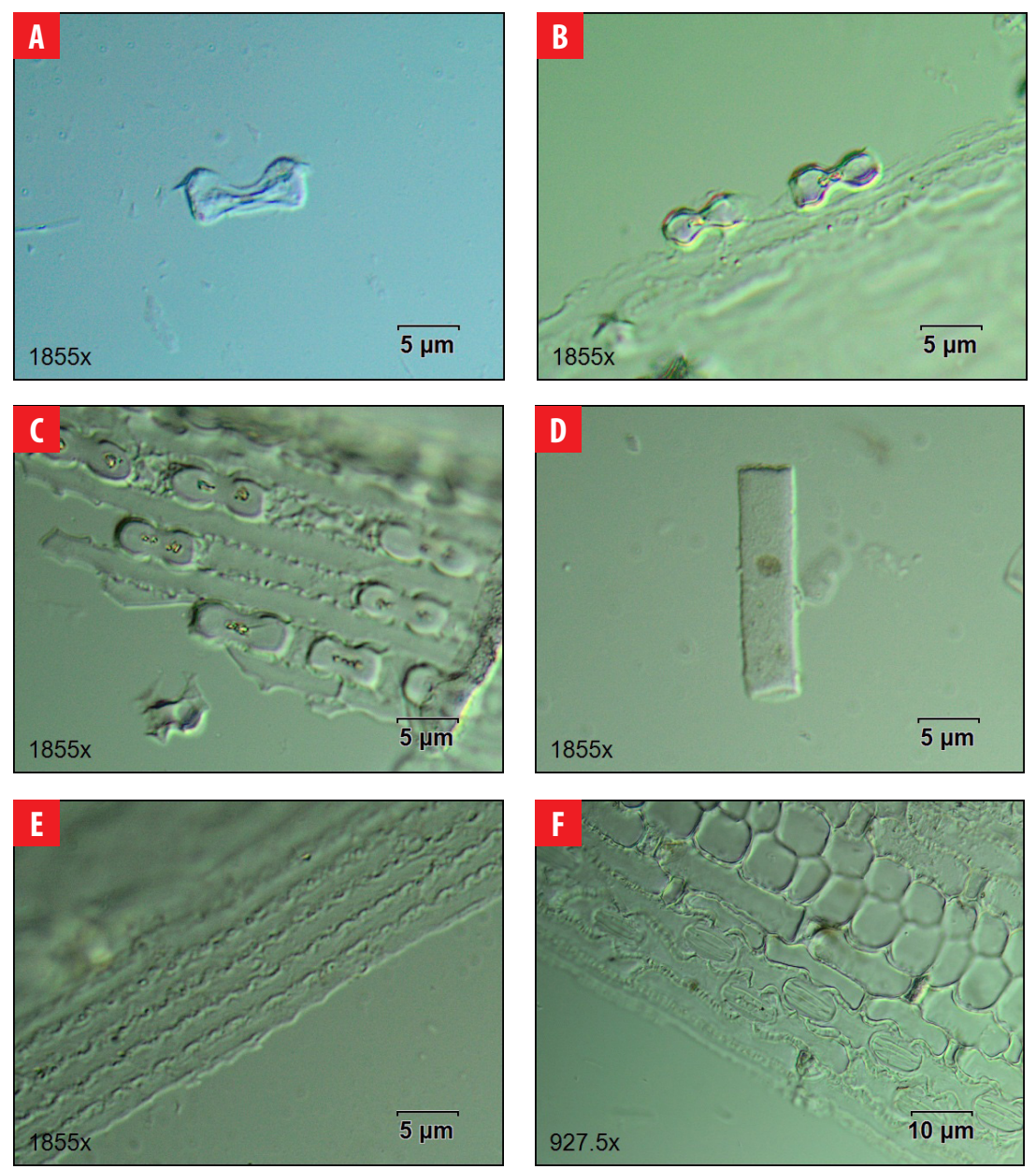
Morphotypes continued: (G) Polyhedral phytoliths; (H) rondel tall narrow flat top; (I) rondel tall pyramidal ovate top; (J) rondel wavy-top; (K) saddle phytoliths; (L) stomate phytoliths
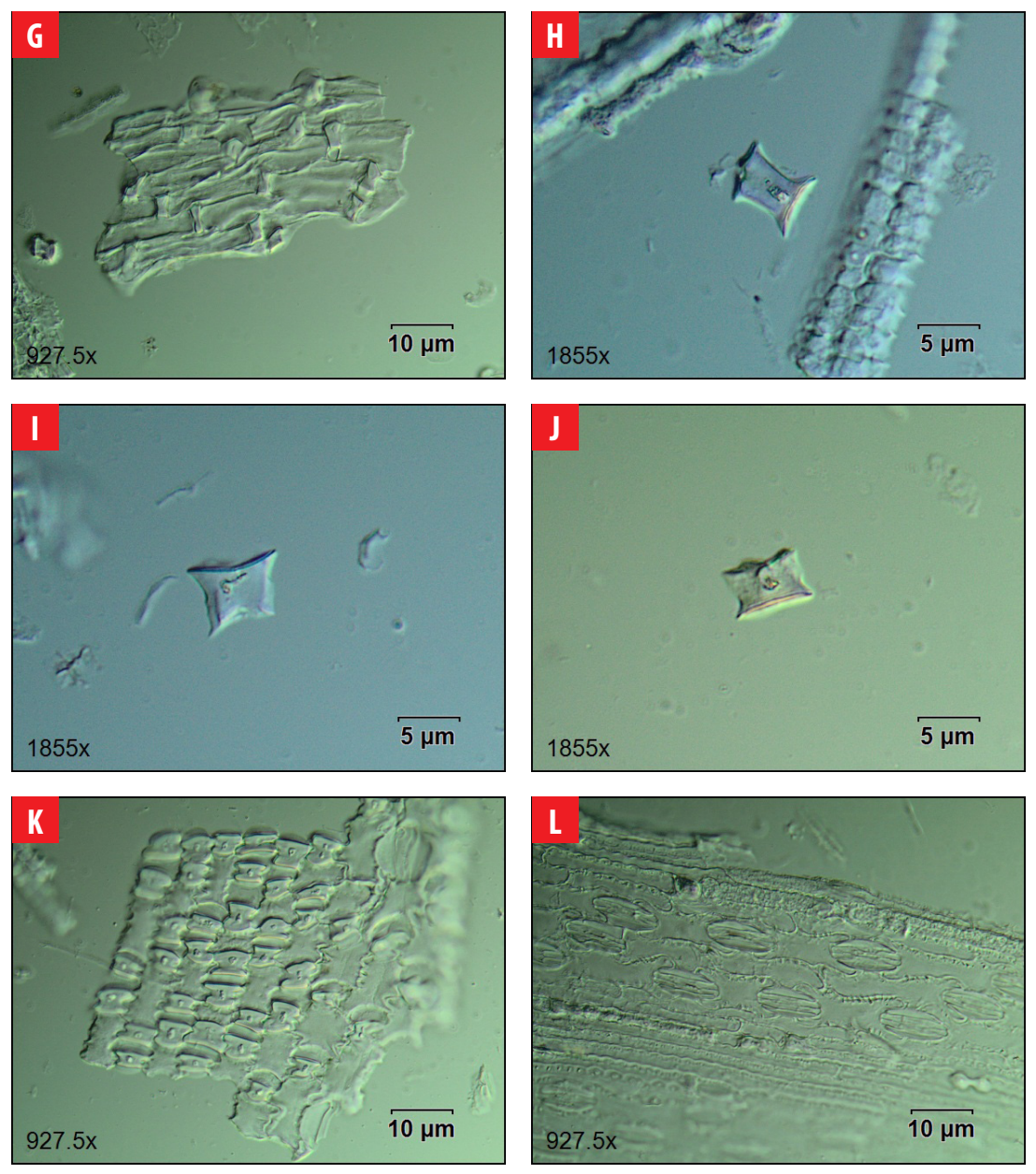


\subsection{Poaceae. Stenotaphrum secundatum (Walter) Kuntze}

Common name: Buffalo grass.

Origin: Native

Part Processed: Leaf, stem

Density: High

Morphotypes: (A \& B) Bilobate concave outer margins short shaft; (C-F) variants of polylobate epidermal short cell.
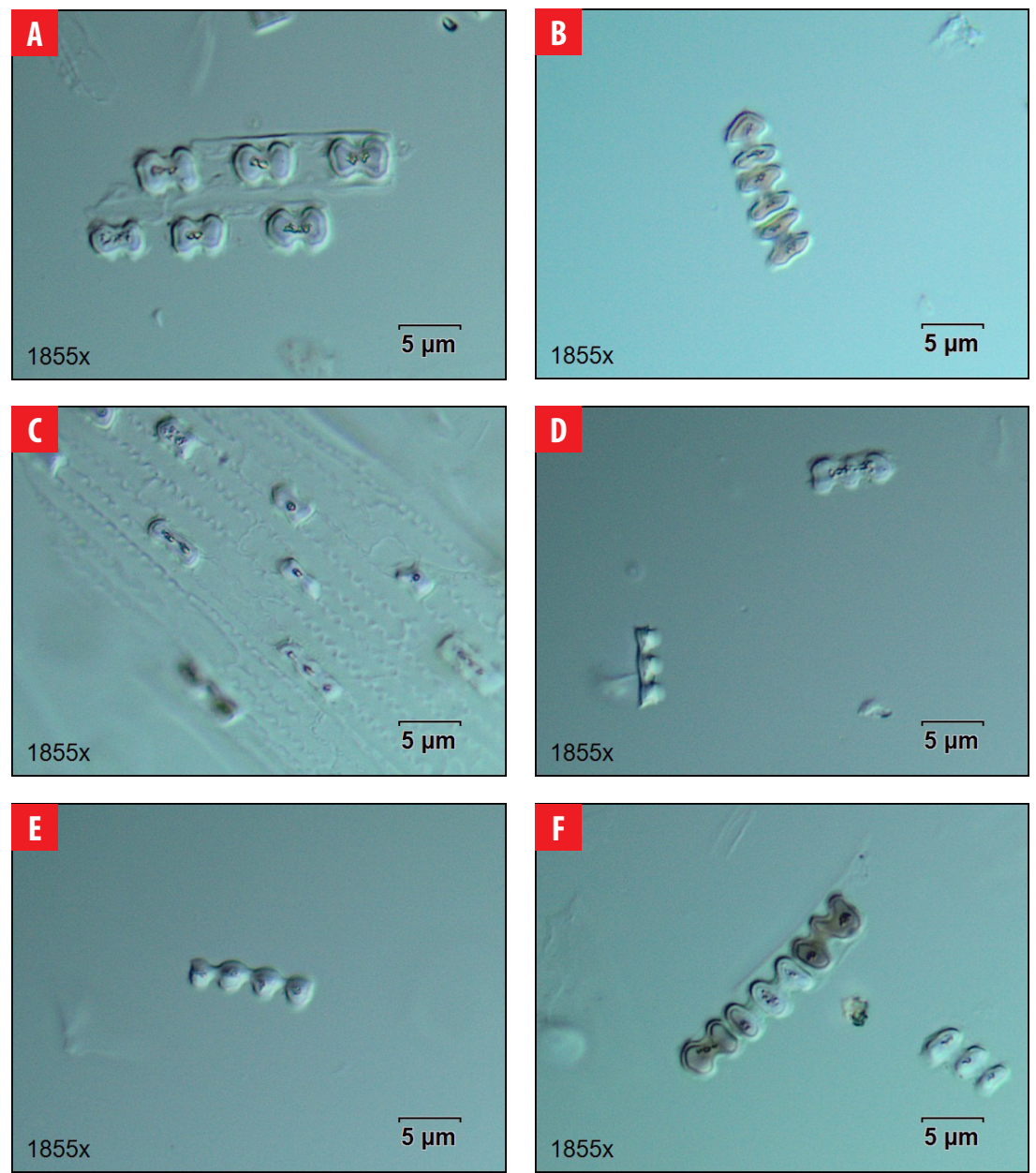
Morphotypes continued: (G \& H) Polylobate epidermal short cell; (I \& J) rondel tall narrow flat top; (K) rondel tall pyramidal ovate top; (L) scutiform lanceolate
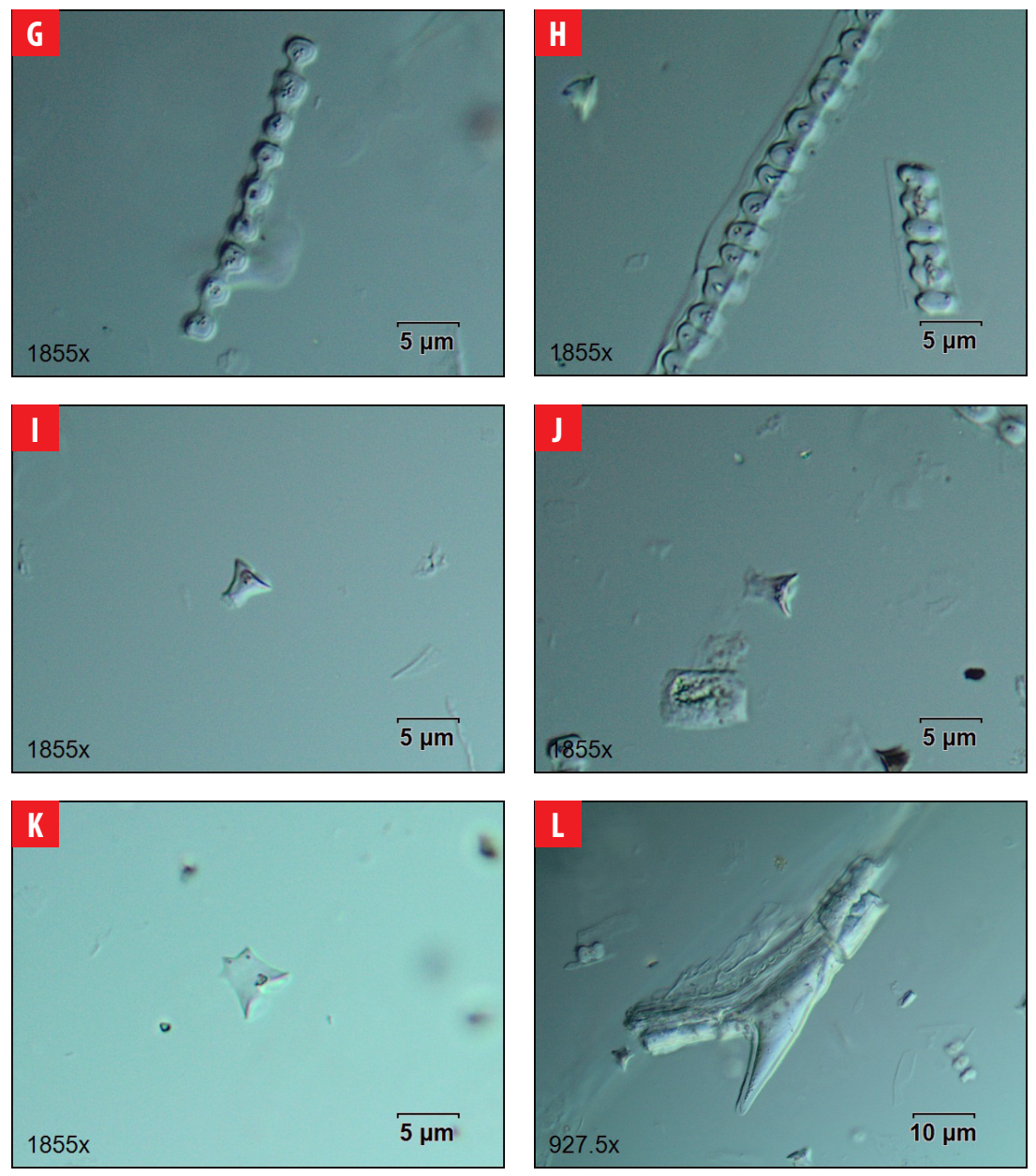
4.31 Rubiaceae. Coffea Arabica L.

Common name: Coffee / Café

Origin: Introduced (Cultivated)

Part Processed: Leaf, stem

Density: Low

Morphotypes: Cylindrical sulcate tracheid phytoliths
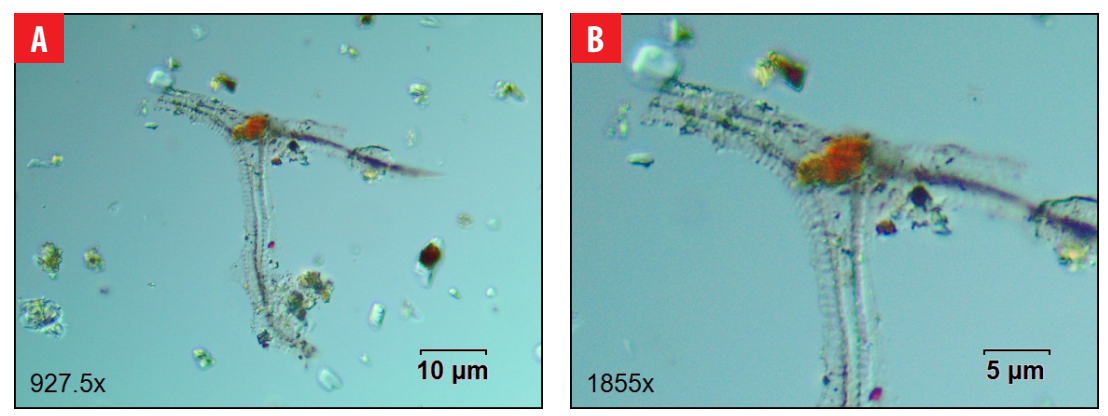

4.32 Rutaceae. Citrus paradisi Macfad.

Common name: Grapefruit / Toronja

Origin: Introduced (Cultivated)

Part Processed: Leaf, stem, wood

Density: LoW

Morphotypes: (A) Globular phytotlith; (B) trapeziform epidermal phytolith
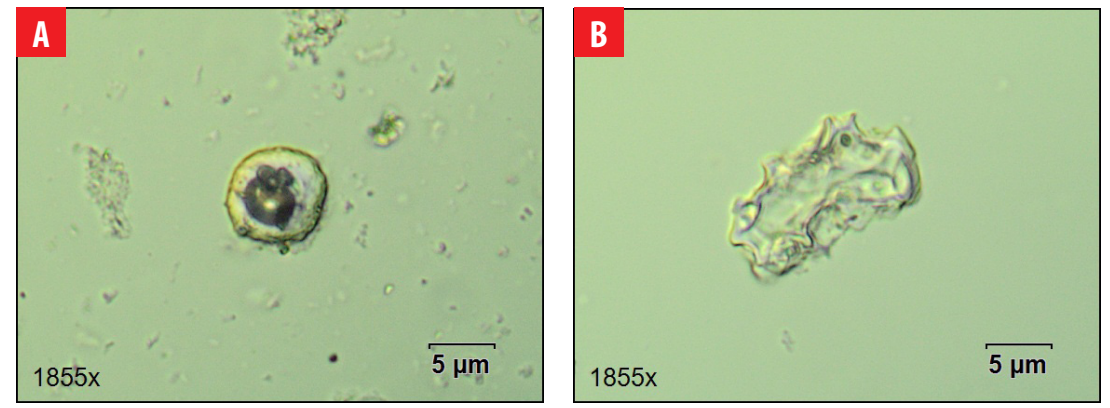
4.33 Rutaceae. Zanthoxylum fagara (L.) Sarg.

Common name: Cat's claw / Uña de Gato

Origin: Native

Part Processed: Leaf, stem, wood

Density: LoW

Morphotypes: (A) Cylindrical sulcate tracheid; (B \& C) hair base; (D) mesophyll epidermal phytoliths
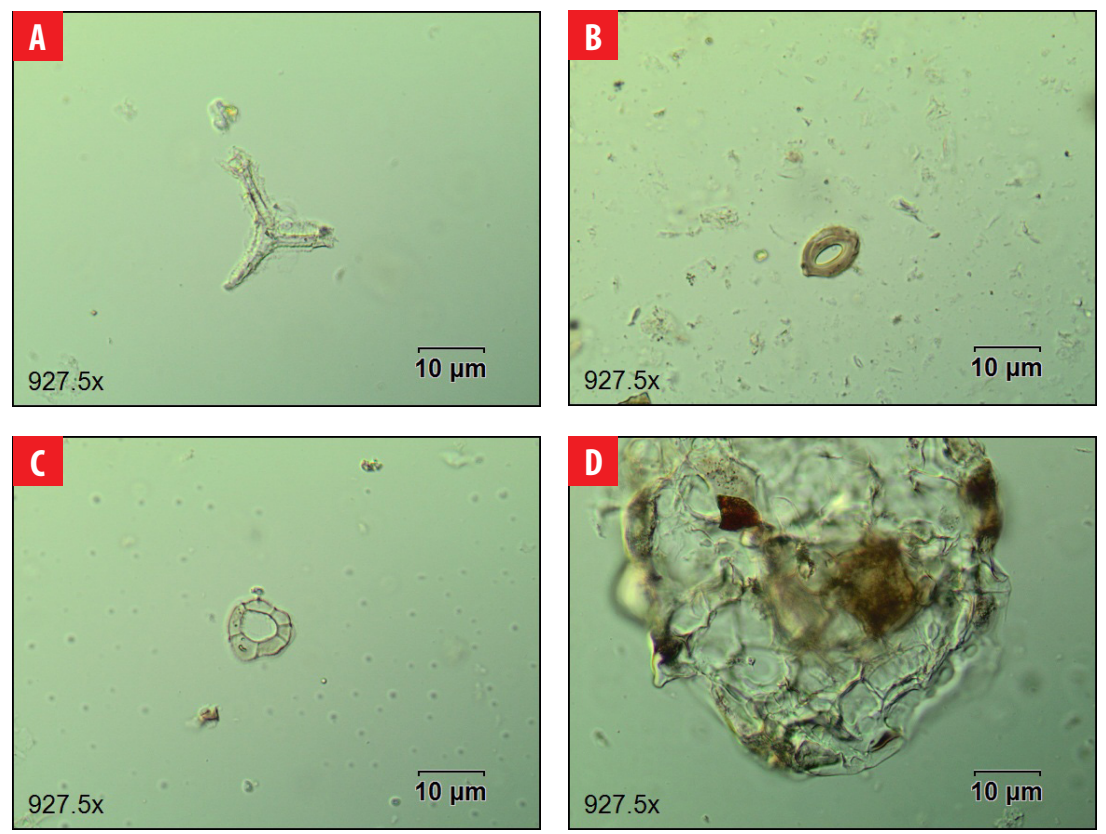

4.34 Solanaceae. Solanum cheesmaniae f. cheesmaniae (Riley) Fosberg.

Common name: Galápagos tomato / Tomatillo

Origin: Endemic

Part Processed: Leaf, stem

Density: LoW

Morphotypes: Mesophyll epidermal phytoliths
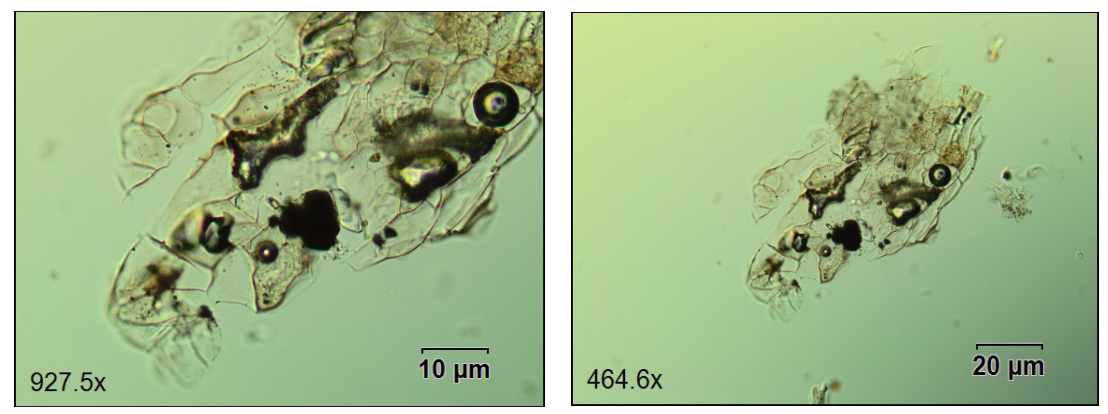


\subsection{Urticaceae. Laportea aestuans (L.) Chew}

Common name: West Indian woodnettle / Ortiga.

Origin: Native (Indigenous taxon)

Part Processed: Leaf, stem

Density: Low

Morphotypes: (A-C) Acicular hair cell; (D) hair base; (E \& F) oblong columellate epidermal cell.
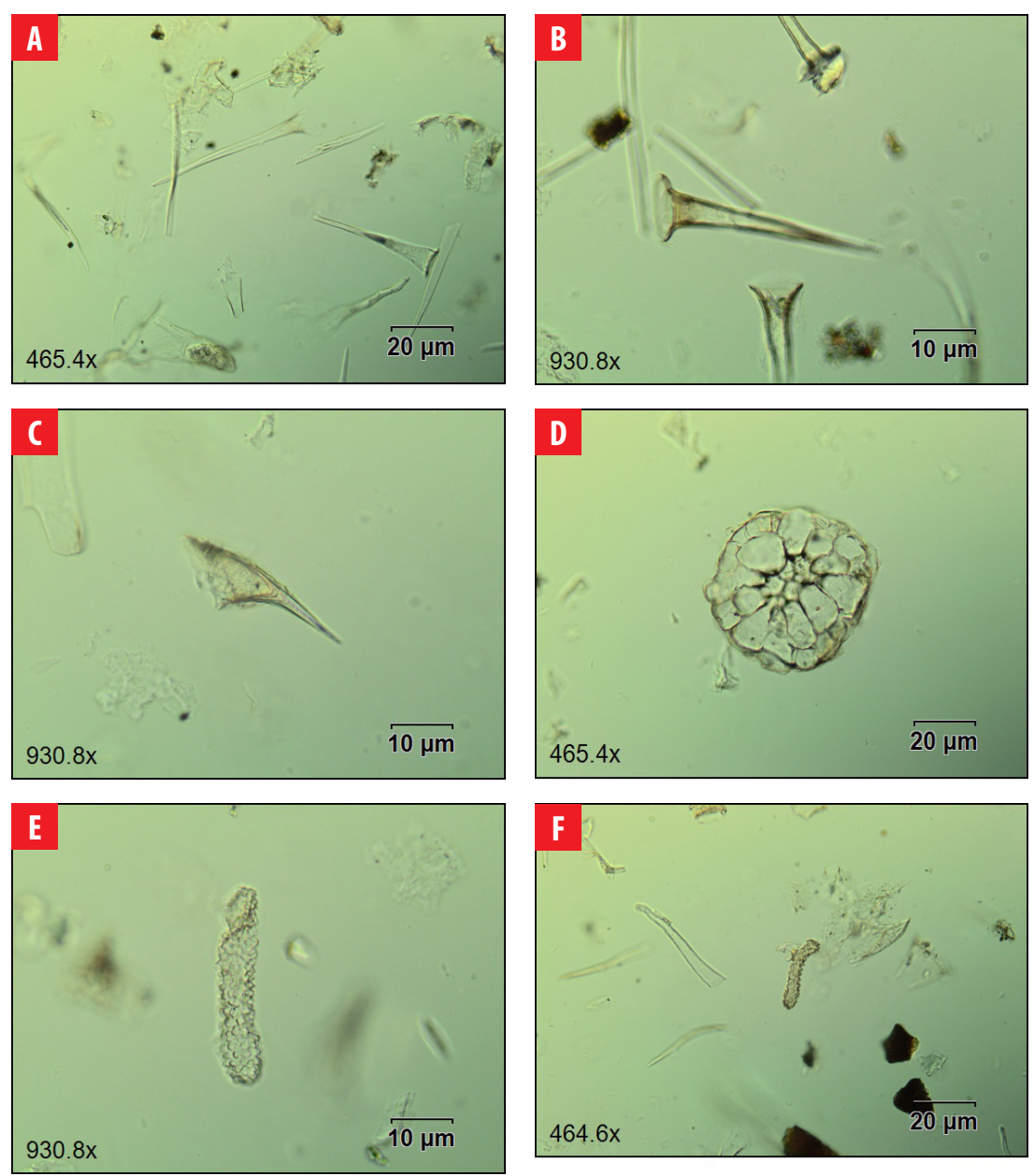


\section{DISCUSSION}

The analysis of phytoliths extracted from modern plants of San Cristóbal does not show significant numbers of diagnostic morphotypes in native and endemic plant species but confirms that grasses are high producers of diagnostic phytoliths. The comparative collection presented here was limited to detecting the production of phytoliths in useful plants for humans such as trees and shrubs, which are generally low producers of diagnostic phytoliths. Further work will contribute to understanding the complete spectrum of phytolith production in the native and endemic vegetation of the island.

The results of this work, however, contributed in suggesting that the introduction of the several species of grasses existing on San Cristóbal today happened with human colonization and the start of intensive agriculture associated with El Progreso plantation. Vegetation clearing and expansion of grasslands were probably executed to sustain grazing activities that were an important economic aspect of the plantation enterprise $[22,52,53]$. The results presented here support the premise that the landscape around the modern village of El Progreso is an anthropogenic landscape resulting from about two centuries of continual agriculture and grazing that started in the 1860s [52]. The modern vegetation of the Agricultural Zone of San Cristóbal Island is a result of vegetation clearing, the introduction of plants and animals, episodes of abandonment of the landscape, and the adaptation of new plant species.

In this regard, Historical Ecology has proved to be a useful framework to investigate aspects of the human history of San Cristóbal Island. Current botanical and palaeoecological research in the Galápagos focuses on understanding the effects of introduced plants and animals on the local ecology in order to reduce its effects. However, it is also important to recognize the historical and political context of the time when these plants were introduced to the archipelago. It is crucial to understand the socio-political context of colonization during the middle 19th century to identify the history of invasive plant species on the archipelago. Most of the existing naturalized plants were intentionally introduced to the Galápagos by colonizers to maintain dietary patterns and cultural traditions [53]. People traveled with known plant species carrying a pre-conceived meaning and use of these species. Other plant taxa were transported to support agriculture and grazing aspects of the plantation enterprise, and some invasive plants traveled with pests or domestic animals. It is necessary, then, to identify the cultural associations between plants and humans during colonization of insular regions.

\section{ACKNOWLEDGMENTS}

This study was conducted with permits from the Galápagos National Park N PC-9314 and N $N^{\circ}$ PC-61-15; National Institute of Cultural Heritage of Ecuador (INPC) N0062014 and N 004-DR4-INPC-2015. Export of soil samples and dried plant material was conducted with the Authorization No.10, INPC'BC'EC"00705. The research was funded by the Government of Ecuador/SENESCYT with a scholarship for doctoral studies to Fernando Astudillo (Beca Convocatoria Abierta 2012 II Fase); a SSHRC Partnership Development Grant No. 890-2013-0013; and the Department of Archaeology of Simon Fraser University (SFU). 
This multidisciplinary project was a collaborative research effort between the Department of Archaeology at Simon Fraser University (Canada), the Department of Anthropology at University of Victoria (Canada), the School of Social Sciences and Humanities of San Francisco de Quito University (Ecuador), the Galápagos Academic Institute for the Arts and Science (GAIAS), and the Galápagos Science Centre (USFQ/ University of North Carolina Chapel Hill). I am grateful to Dr. Carlos Mena, MA. Juan Pablo Muñoz, Ing. Leandro Vaca, and Ing. Luis Tasipanta at the Galápagos Science Centre; Dr. Catherine D'Andrea, Shannon Wood, and Peter Locher at SFU; and to all the people of El Progreso, especially Paulina Cango, Edy Becerra, and Jeffres Malaga.

\section{AUTHOR CONTRIBUTIONS}

The author was in charge of the conceptualization, formal analysis, investigation, methodology, resources, visualization, and writing of this paper. 


\section{REFERENCES}

[1] Bungartz, F., Herrera, H., Jaramillo, P., Tirado, N., Jiménez-Uzcátegui, G., Ruiz, D., ... Ziemmeck, F. (Eds.). (2009). Charles Darwin Foundation Galapagos Species Checklist - Lista de Especies de Galápagos de la Fundación Charles Darwin. Puerto Ayora: Charles Darwin Foundation. Retrieved from http://www.darwinfoundation.org/datazone/checklists/

[2] Guézou, A., Chamorro, S., Pozo, P., Guerrero, A. M., Atkinson, R., Buddenhagen, C., ... Gardener, M. R. (2016). CDF Checklist of Galapagos Introduced Plants - FCD Lista de especies de Plantas introducidas de Galápagos. In Charles Darwin Foundation Galapagos Species Checklist - Lista de Especies de Galápagos de la Fundación Charles Darwin. Puerto Ayora: Charles Darwin Foundation / Fundación Charles Darwin. Retrieved from http://www.darwinfoundation.org/ datazone/checklists/introduced-species/introduced-plants/

[3] Jaramillo Díaz, P., \& Guézou, A. (2010). List of all Known Species from the Galapagos Islands - Lista de todas las especies conocidas de las Islas Galápagos. In F. Bungartz, H. Herrera, \& P. Jaramillo (Eds.), List of all Known Species from the Galapagos Islands - Lista de todas las especies conocidas de las Islas Galápagos. Online repository of the Charles Darwin Foundation/Fundación Charles Darwin, Puerto Ayora, Galápagos: http://www.darwinfoundation. org/datazone/checklists/

[4] Jaramillo Díaz, P., Guézou, A., Mauchamp, A., \& Tye, A. (2014). CDF Checklist of Galapagos Flowering Plants - FCD Lista de especies de Plantas con flores de Galápagos. In Charles Darwin Foundation Galapagos Species Checklist - Lista de Especies de Galápagos de la Fundación Charles Darwin. Puerto Ayora: Charles Darwin Foundation / Fundación Charles Darwin, Retrieved from http://www.darwinfoundation.org/datazone/checklists/vascular-plants/magnoliophyta/

[5] McMullen, C. K. (1999). Flowering plants of the Galapagos. Ithaca, NY: Cornell University Press.

[6] Gromme, S., Mankinen, E. A., \& Prévot, M. (2010). Time-averaged paleomagnetic field at the equator: Complete data and results from the Galapagos Islands, Ecuador. Geochemistry, Geophysics, Geosystems, 11(11), Q11009. doi: https:// doi.org/10.1029/2010GC003090

[7] McBirney, A. R., \& Williams, H. (1969). Geology and petrology of the Galapagos Islands (Vol. 118). Geological Society of America.

[8] Simkin, T. (1984). Geology of Galapagos. Biological Journal of the Linnean Society, 21(1-2), 61-75. doi: https://doi. org/10.1111/j.1095-8312.1984.tb02053.x

[9] Stoops, G. (2014). Soils and Paleosoils of the Galápagos Islands: What We Know and What We Don't Know, A MetaAnalysis. Pacific Science, 68(1), 1-17. doi: https://doi.org/10.2984/68.1.1

[10] Franz, H. (1980). Old soils and land surfaces on the Galápagos islands. GeoJournal, 4(2), 182-184. doi: https://doi. org/10.1007/BF00705525

[11] Trueman, M., \& d'Ozouville, N. (2010). Characterizing the Galapagos terrestrial climate in the face of global climate change. Galapagos Research, 67, 26-37.

[12] Wiggins, I. I. L., Porter, D. M., \& Anderson, E. F. (1971). Flora of the Galapagos islands. Stanford University Press.

[13] Lee, J. (2006). Archaeological Charcoal of the Galapagos Islands. A species analysis of charcoal remains from historic campsites on Santiago and Santa Cruz Islands (MSc. Dissertation). Oxford University.

[14] McMullen, C. K. (1999). Flowering plants of the Galapagos. Ithaca, NY: Cornell University Press.

[15] Guézou, A., Trueman, M., Buddenhagen, C. E., Chamorro, S., Guerrero, A. M., Pozo, P., \& Atkinson, R. (2010). An Extensive Alien Plant Inventory from the Inhabited Areas of Galapagos. PLoS ONE, 5(4). doi: https://doi.org/10.1371/ journal.pone.0010276

[16] Anderson, A., Stothert, K., Martinsson-Wallin, H., Wallin, P., Flett, I., Haberle, S., . . Rhodes, E. (2016). Reconsidering Precolumbian Human Colonization in the Galápagos Islands, Republic of Ecuador. Latin American Antiquity, 27(2), 169-183. doi: https://doi.org/10.7183/1045-6635.27.2.169

[17] Latorre, 0. (2002). Manuel J. Cobos: Su Vida y Su Obra. Quito: Agencia Española de Cooperación Internacional.

[18] Latorre, 0. (2011). Historia Humana de Galápagos. Nuevas Investigaciones. Quito: Academia Nacional de Historia.

[19] Albert, R. M., \& Weiner, S. (2001). Study of phytoliths in prehistoric ash layers from Kebara and Tabun caves using a quantitative approach. In J. D. Meunier \& F. Colin (Eds.), Phytoliths: Applications in earth sciences and human history (pp. 251-266). Lisse: Taylor \& Francis. 
[20] Mercader, J., Bennett, T., Esselmont, C., Simpson, S., \& Walde, D. (2011). Soil phytoliths from miombo woodlands in Mozambique. Quaternary Research, 75(1), 138-150. doi: https://doi.org/10.1016/j.yqres.2010.09.008

[21] Mercader, J., Astudillo, F., Barkworth, M., Bennett, T., Esselmont, C., Kinyanjui, R., \& Walde, D. (2010). Poaceae phytoliths from the Niassa Rift, Mozambique. Journal of Archaeological Science, 37(8), 1953-1967. doi: https://doi. org/10.1016/j.jas.2010.03.001

[22] Astudillo, F. J. (2018). Soil phytoliths as indicators of initial human impact on San Cristóbal Island, Galápagos. Palaeogeography, Palaeodlimatology, Palaeoecology, 490(Supplement C), 522-532. doi: https://doi.org/10.1016/j. palaeo.2017.11.038

[23] Madella, M., Alexandre, A., \& Ball, T. (2005). International Code for Phytolith Nomenclature 1.0. Annals of Botany, 96(2), 253-260. doi: https://doi.org/10.1093/aob/mci172

[24] Albuquerque, E. S. B. de, Braga, J. M. A., \& Vieira, R. C. (2013). Morphological characterisation of silica phytoliths in Neotropical Marantaceae leaves. Plant Systematics and Evolution, 1-12. doi: https://doi.org/10.1007/s00606-013-0823-9

[25] Dickau, R., Whitney, B. S., Iriarte, J., Mayle, F. E., Soto, J. D., Metcalfe, P., ... Killeen, T. J. (2013). Differentiation of neotropical ecosystems by modern soil phytolith assemblages and its implications for palaeoenvironmental and archaeological reconstructions. Review of Palaeobotany and Palynology, 193, 15-37. doi: https://doi.org/10.1016/j. revpalbo.2013.01.004

[26] Dickau, R., Bruno, M. C., Iriarte, J., Prümers, H., Jaimes Betancourt, C., Holst, I., \& Mayle, F. E. (2012). Diversity of cultivars and other plant resources used at habitation sites in the Llanos de Mojos, Beni, Bolivia: Evidence from macrobotanical remains, starch grains, and phytoliths. Journal of Archaeological Science, 39(2), 357-370. doi: https://doi.org/10.1016/j.jas.2011.09.021

[27] Ezell, K., Pearsall, D., \& Zeidler, J. (2006). Root and tuber phytoliths and starch grains document manioc (Manihot esculenta) arrowroot (Maranta arundinacea) and llerén (Calathea sp.) at the real alto site Ecuador. Economic Botany, 60(2), 103-120. doi: https://doi.org/10.1663/0013-0001(2006)60[103:RATPAS]2.0.C0;2

[28] Iriarte, J., Glaser, B., Watling, J., Wainwright, A., Birk, J. J., Renard, D., .. McKey, D. (2010). Late Holocene Neotropical agricultural landscapes: phytolith and stable carbon isotope analysis of raised fields from French Guianan coastal savannahs. Journal of Archaeological Science, 37(12), 2984-2994. doi: https://doi.org/10.1016/j.jas.2010.06.016

[29] Korstanje, M. A., \& Cuenya, P. (2010). Ancient agriculture and domestic activities: a contextual approach studying silica phytoliths and other microfossils in soils. Environmental Archaeology, 15(1), 43-63. doi: https://doi. org/10.1179/146141010X12640787648739

[30] Morcote-Ríos, G., Giraldo-Cañas, D., \& Raz, L. (2015). Catálogo ilustrado de fitolitos contemporáneos con énfasis arqueológico y paleoecológico. I. Gramíneas Amazónicas/ Catalogue of Contemporary Phytoliths for Archaeology and Paleoecology. I. Amazonian Grasses. Bogotá: Universidad Nacional de Colombia.

[31] Pearsall, D. M. (2016). The Phytoliths in the Flora of Ecuador Project: Perspectives on Phytolith Classification, Identification, and Establishing Regional Phytolith Databases. Journal of Archaeological Science. doi: https://doi. org/10.1016/j.jas.2015.06.014

[32] Pearsall, D. M., Chandler-Ezell, K., \& Chandler-Ezell, A. (2003). Identifying maize in neotropical sediments and soilsusing cob phytoliths. Journal of Archaeological Science, 30(5), 611-627.

[33] Perry, L., Dickau, R., Zarrillo, S., Holst, I., Pearsall, D. M., Piperno, D. R., ... Zeidler, J. A. (2007). Starch Fossils and the Domestication and Dispersal of Chili Peppers (Capsicum spp. L.) in the Americas. Science, 315(5814), 986-988. doi: https://doi.org/10.1126/science.1136914

[34] Piperno, D. R. (2009). Identifying crop plants with phytoliths (and starch grains) in Central and South America: A review and an update of the evidence. Quaternary International, 193(1-2), 146-159. doi: https://doi.org/10.1016/j. quaint.2007.11.011

[35] Piperno, D. R. (2006). Phytoliths: A comprehensive guide for archaeologists and paleoecologists. Lanham, MD: AltaMira Press.

[36] Piperno, D. R., \& Pearsall, D. M. (1998). The silica bodies of tropical American grasses: Morphology, taxonomy, and implications for grass systematics and fossil phytolith identification. Washington, D.C.: Smithsonian Institution Press.

[37] Watling, J., \& Iriarte, J. (2013). Phytoliths from the coastal savannas of French Guiana. Quaternary International, 287, 162-180. doi: https://doi.org/10.1016/j.quaint.2012.10.030 
[38] Blinnikov, M. S., Bagent, C. M., \& Reyerson, P. E. (2013). Phytolith assemblages and opal concentrations from modern soils differentiate temperate grasslands of controlled composition on experimental plots at Cedar Creek, Minnesota. Quaternary International, 287, 101-113. doi: https://doi.org/10.1016/j.quaint.2011.12.023

[39] Brown, D. A. (1984). Prospects and limits of a phytolith key for grasses in the central United States. Journal of Archaeological Science, 11(4), 345-368. doi: https://doi.org/10.1016/0305-4403(84)90016-5

[40] Fernández Honaine, M., Osterrieth, M. L., \& Zucol, A. F. (2009). Plant communities and soil phytolith assemblages relationship in native grasslands from southeastern Buenos Aires province, Argentina. CATENA, 76(2), 89-96. doi: https://doi.org/10.1016/j.catena.2008.09.011

[41] Fernández Honaine, M., Zucol, A. F., \& Osterrieth, M. L. (2006). Phytolith Assemblages and Systematic Associations in Grassland Species of the South-Eastern Pampean Plains, Argentina. Annals of Botany, 98(6), 1155-1165. doi: https://doi.org/10.1093/aob/mcl207

[42] Fredlund, G. G. (2005). Grass Phytolith Analysis. Plains Anthropologist, 50(196), 63-68. doi: https://doi.org/10.1179/ pan. 2005.032

[43] Gallego, L., \& Distel, R. A. (2004). Phytolith Assemblages in Grasses Native to Central Argentina. Annals of Botany, 94(6), 865-874. doi: https://doi.org/10.1093/aob/mch214

[44] Iriarte, J. (2003). Assessing the feasibility of identifying maize through the analysis of cross-shaped size and threedimensional morphology of phytoliths in the grasslands of southeastern South America. Journal of Archaeological Science, 30(9), 1085-1094. doi: https://doi.org/10.1016/S0305-4403(02)00164-4

[45] Mulholland, S. C. (1989). Phytolith shape frequencies in North Dakota grasses: a comparison to general patterns. Journal of Archaeological Science, 16(5), 489-511. doi: https://doi.org/10.1016/0305-4403(89)90070-8

[46] Rudall, P. J., Prychid, C. J., \& Gregory, T. (2014). Epidermal Patterning and Silica Phytoliths in Grasses: An Evolutionary History. The Botanical Review, 80(1), 59-71. doi: https://doi.org/10.1007/s12229-014-9133-3

[47] Twiss, P. C., Meunier, J. D., \& Colin, F. (2001). A curmudgeon's view of grass phytolithology. Phytoliths: Applications in Earth Sciences and Human History, 7-25.

[48] Twiss, P. C. (1992). Predicted world distribution of C 3 and C 4 grass phytoliths. Phytolith Systematics, Emerging Issues, Advances in Archaeological and Museum Science, 1, 113-128.

[49] Twiss, P. C., Suess, E., \& Smith, R. M. (1969). Morphological classification of grass phytoliths. Soil Science Society of America Journal, 33(1), 109-115.

[50] Gu, Y., Liu, H., Wang, H., Li, R., \& Yu, J. (2016). Phytolith as a method of identification for three genera of woody bamboos (Bambusoideae) in tropical southwest China. Journal of Archaeological Science, 68, 46-53. doi: https://doi. org/10.1016/j.jas.2015.08.003

[51] Parr, J., Sullivan, L., \& Quirk, R. (2009). Sugarcane phytoliths: Encapsulation and sequestration of a long-lived carbon fraction. Sugar Tech, 11(1), 17-21. doi: https://doi.org/10.1007/s12355-009-0003-y

[52] Astudillo, F. J. (2017). Environmental Historical Archaeology of the Galápagos Islands: Paleoethnobotany of Hacienda EI Progreso (1870-1904) (PhD Dissertation. Department of Archaeology). Simon Fraser University, Burnaby, BC.

[53] Astudillo, F.J. (2018). Environmental and historical archaeology of the Galápagos islands: Archaeobotany of Hacienda El Progreso, 1870-1920. Vegetation History and Archaeobotany, 27(5), 737-751. https://doi.org/https://doi. org/10.1007/s00334-018-0668-9 